\title{
Isolation of Prolidase from Amniotic Fluid and Study of its Kinetic and Affinity Properties Towards Pharmacological Compounds
}

\author{
Luay Abed Al-Helaly \\ Department of Chemistry / College of Science \\ Mosul University \\ Mosul- Iraq \\ Luayhelaly@uomosul.edu.iq
}

DOI: $\underline{10.33899 / \text { edusi.2019.162958 }}$

\author{
Received \\ 07 / 01 / 2019
}

\author{
Accepted \\ 27 / 02 / 2019
}

\begin{abstract}
The research included the isolation of prolidase from human amniotic fluid using different biochemical techniques, One proteinous peak had been isolated by gel filtration using sephadex (G-50) and from sephadex (G-100) that produced by ammonium sulphate precipitation $(60 \%)$ after dialysis. The approximately molecular weight of the enzyme using gel filtration chromatography (G-100) was (52269.7) Dalton and specific activity of $13516.6 \mathrm{unit} / \mathrm{mg}$ protein with 75 fold of purification. The results showed that the optimum conditions of purified enzyme from amniotic fluid were at $(50 \mu \mathrm{g} / \mathrm{ml})$ of protein as a source of the enzyme using $(60 \mathrm{mM} / \mathrm{L})$ Tris$\mathrm{HCl}$ buffer solution at $\mathrm{pH}(8.0)$ act for $(32)$ minutes at $\left(39^{\circ} \mathrm{C}\right)$. Using Line WeaverBurk plot, the values of maximum velocity $\left(V_{\max }\right)$ and Michaelis constant $\left(K_{\mathrm{m}}\right)$ were found to be (3448.2 U/L) and (10 mM/L) respectively using Gly-Pro as a substrate.

Finally, also, involved the study of the effect pharmacological chemicals compounds on the enzyme activity, the results showed that the drug chemical compounds for type ceramide, metoclopramide, pseudoephedrine, diphenhydramine$\mathrm{HCl}$, chloramphnicol, paracetamol and allopurinol give the inhibition type competitive, with increased in $K_{\mathrm{m}}$ value to $66.6,71.42,52.63,55.55,83.33,90.9$ and $100.0 \mathrm{mM} / \mathrm{L}$ respectively for inhibitors above, while the others pharmacological compounds for theophlline anhydrous, caffeine anhydrous, metronidazole and chlorpheniramine maleate, give the inhibition type of non-competitive with decreased in $V_{\max }$ values to $2173.9,2439.0,2000.0$ and $2325.58 \mathrm{U} / \mathrm{L}$ respectively, but dexathamazone was an activator to the prolidase approximately $27.18 \mathrm{U} / \mathrm{L}$.
\end{abstract}

Keywords: Isolation, Enzyme, Prolidase, Amniotic fluid, Inhibitors, Activators. 
عزل إنزيم برولايديز من السائل الأمنيوني ودراسة صفاته الحركية وألفته تجاه المركبات الدوائية

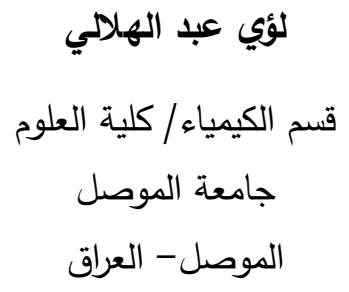

\section{Luayhelaly@uomosul.edu.iq}

DOI: $\underline{10.33899 / \text { edusj.2019.162958 }}$

القبول

2019 / 02 / 27
الاستلام

2019 / 01 / 07

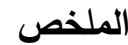

تضمن البحث عزل إنزيم برولايديز من سائل الأمنيوني باستعمال التقنيات الحياتية المختلفة، اذ تم

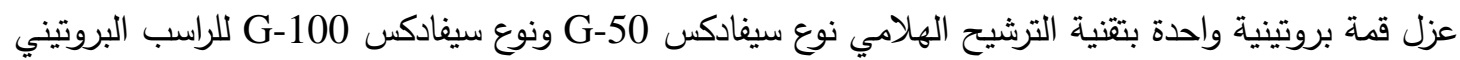
الناتج من عملية الترسيب بكبريتات الامونيوم (60\%) بعد عملية الفرز الغثائي. وقدر الوزن الجزيئي التقريبي للإنزيم باستعمال تقنية الترشيح الهلامي نوع (G-100) التي كانت بحدود 52269.7 دالتون، وبلغت فعاليته النوعية 13516.6 وحدة إنزيم/ملغم من البروتين ذي عدد مرات تتقية وصلت 75 مرة. أظهرت النتائج أن الظروف المثلى للإنزيم المنقى من سائل الأمنيوني عند استعمال تركيز 50 مايكروغرام/مل للبروتين كمصدر للإنزيم باستعمال المحلول المنظم ترس- حامض الهيدروكلوريك بتركيز 60 ملي مول/لتر وعند أس هيدروجيني

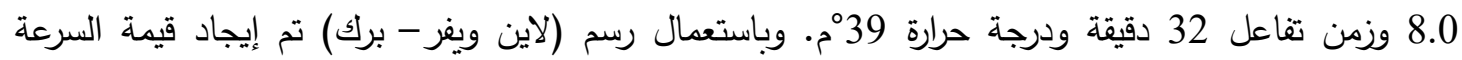

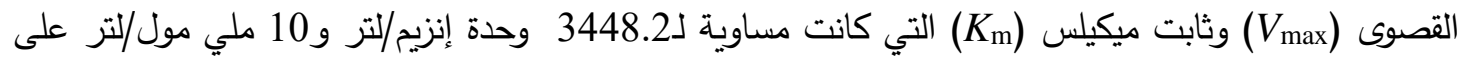
التوالي عند استعمال مادة الأساس نوع كلايسين-برولين (Gly-Pro). وأخيراً تم دراسة تأثير بعض المركبات الكيميائية الدوائية على فعالية الإنزيم، وبينت النتائج أن المركبات الكيميائية الدوائية من السيراميد وميتوكلوبراميد وبسيدوفيدرين وداي فيهايدرامين-هايدروكلورايد وكلورامفينكول وباراسيتامول وألوبيرانول اعطوا تثبيطاً من نوع التتافسي، الذين كانت لهم زيادة في قيمة Km 71.42، 52.63، 55.55، 83.33، 90.9، الدوائية من نوع ثيوفيلين وكافايين وميترونيدازول وكلورفينيرامين ماليت اعطوا تثبيطاً من النوع غير التنافسي، ووصل الانخفاض في قيمة Vmax للمثبطات من هذا النوع الى 2173.9، وحدة إنزيم/لتر على التوالي، ولكن لوحظ ان الدكساثامازون منشط للإنزيم وبمقدار 27.18 وحدة إنزيم/لتر . الكلمات المفتاحية: عزل، إنزيم، برولايديز، السائل الأمنيوني، مثبطات، منشطات. 


\section{المقدمة}

يعد إنزيم البرولايديز [E.C 3.4.13.9] من إنزيمات امينوببتايديز الحاوية على وحدتين ثنائية متجانسة

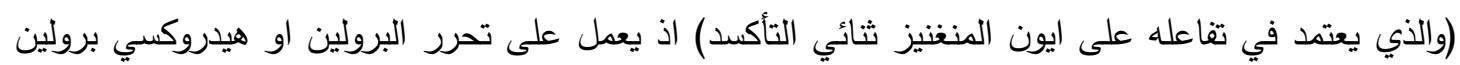

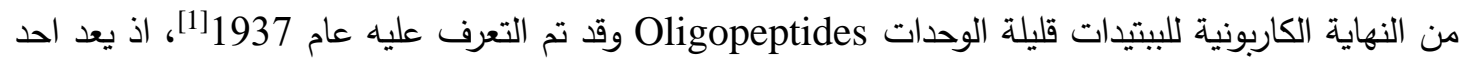
الإنزيمات التي تثارك في بناء الكولاجين وله علاقة في معدلات تحولات الكولاجين [2]، والكولاجين من البروتينات

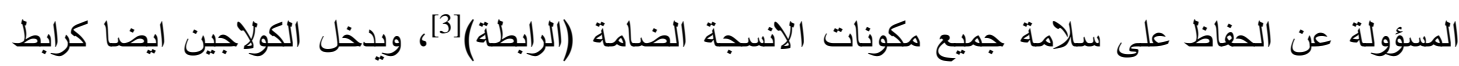
ومكون لمستقبلات لها دور مهم في نقل الاشارات التي تتظم نقل الايون وايض الدهون وتتشيط إنزيم الكاينيز والتعبير الجيني، لذلك فإن التغيير في الكمية والتركيب والتوزيع للكولاجين في الانسجة يمكن ان يؤثر على التى

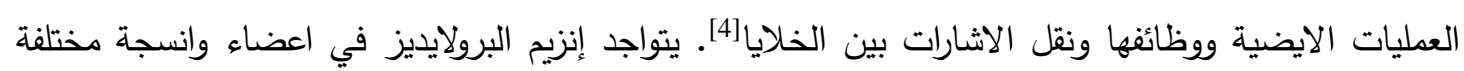
وله وظائف عدة على سبيل المثال تقويض البروتينات وتحولات وتتظيم بناء الكولاجين[5] وفي نمو الخلية

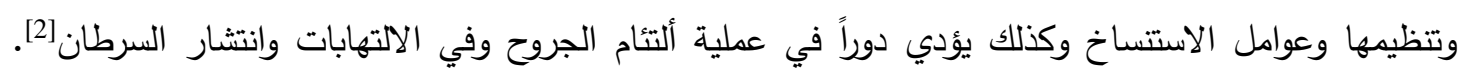
فضلا عن ذلك فالإنزيم يشارك في عملية تظظيم انتاج جذر نيتريك اوكسايد (وهو احد المرسلات الثانوية داخل الجسم) ولذلك فإن الإنزيم له دور بارز مع العديد من الوظائف الحيوية والفسلجية نتيجة علاقته دع نيتئريك

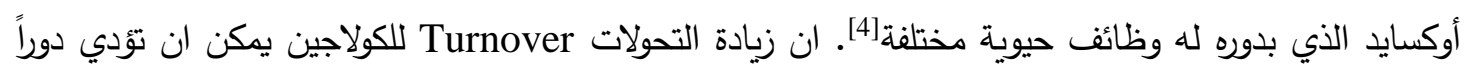

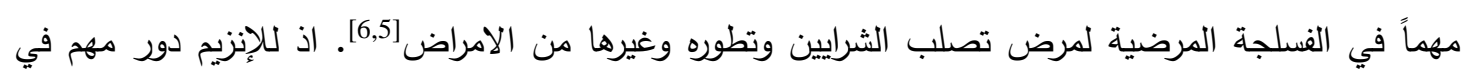

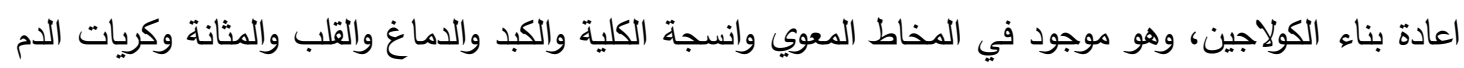

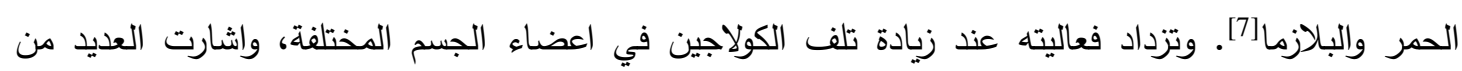

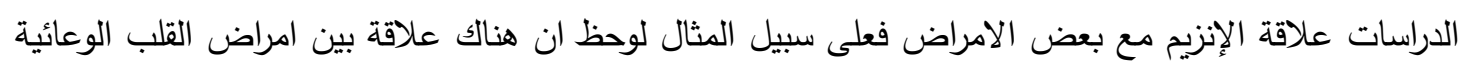

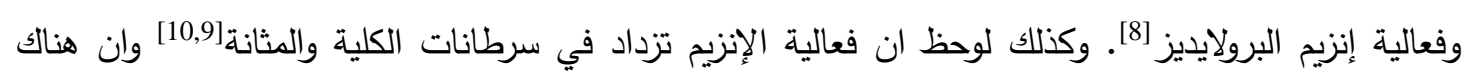

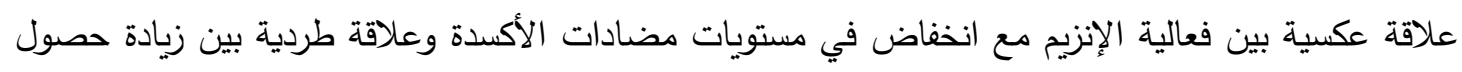

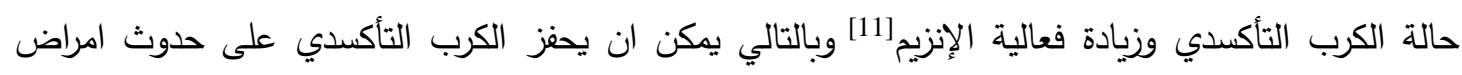

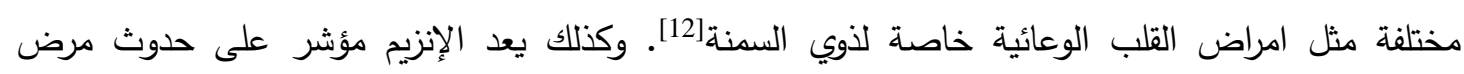
متلازمة المبيض المتعدد التكيسات Polycystic ovary syndrome وله علاقة طردية مع عدد التكيسات

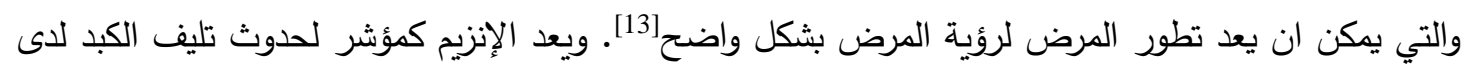

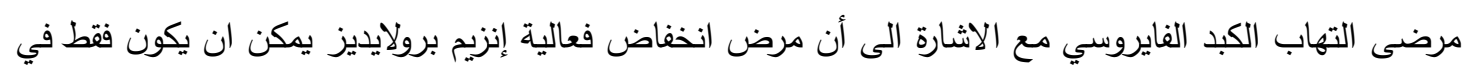

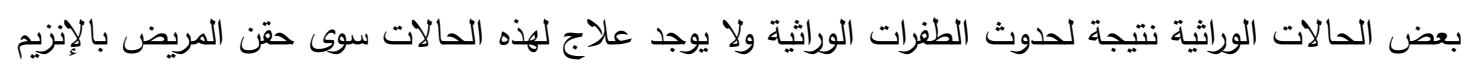
بعد ان يتم عزله من مصادر مختلفة[14]. علاوة على ذلك يدخل إنزيم البرولايديز في وظائف حيوية وتطبيقية اخرى اذ يدخل في عملية تحطيم المركبات السامة العضوية الفوسفاتية[15] وذلك بعملية تحلل اواصر الفوسفور -الفلور P-F والفسفور - الاوكسجين ولفين من Piosensor لتحديد نسبة المركبات العصبية السامة

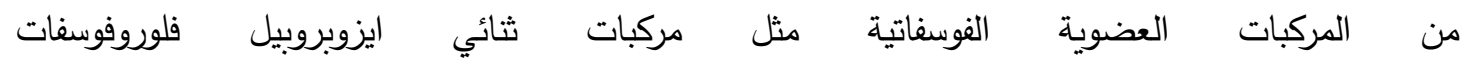
Diisopropylfluorophosphate ازالة تلك المركبات السامة السابقة الذكر [15]، وايضا يدخل في صناعة الجبن من اجل تحسين نوعيته[118)، علاوة على ذلك، فإن الإنزيم يستعمل لأغراض علاجية في المرضى الذين لديهم نقص في هذا الإنزيم] [19]. ونتيجة لجميع تلك الوظائف الحيوية والتطبيقات المختلفة للإنزيم فقد حددت الهداف هذئ هذه الدراسة الى عزل إنزيم برولايديز 
من السائل الأمنيوني باستعمال تتنيات مختلفة ومن ثم دراسته من الناحية الحركية وظروف عمله المثلى وتأثير المركبات الكيميائية الدوائية عليه، إذ أن لدراسة التأثيرات التثبيطية او التتشيطية على فئه فعالية إنزيم البرولايديز

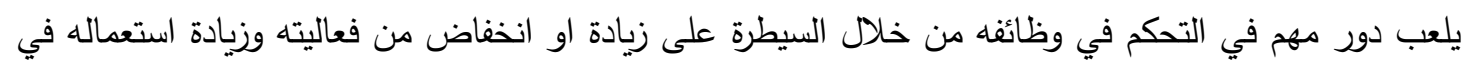

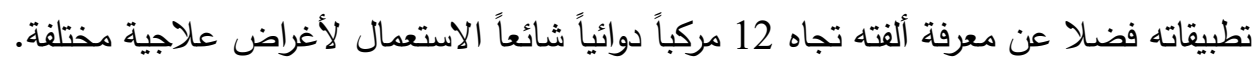

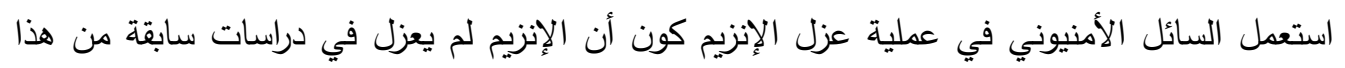

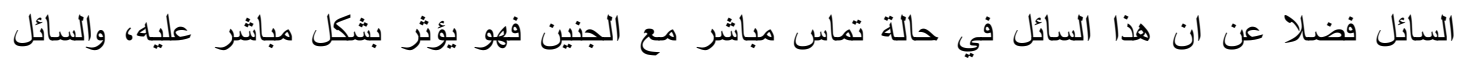

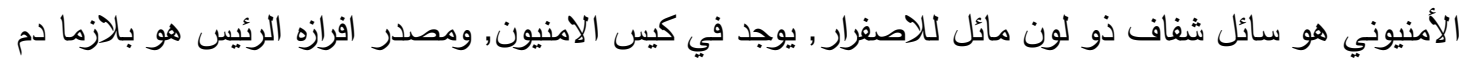

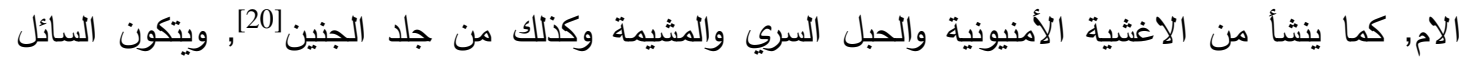

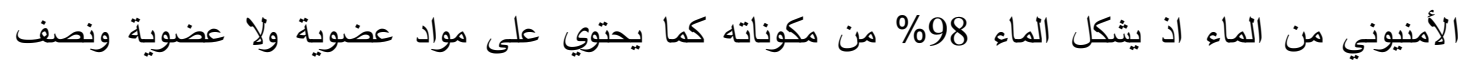

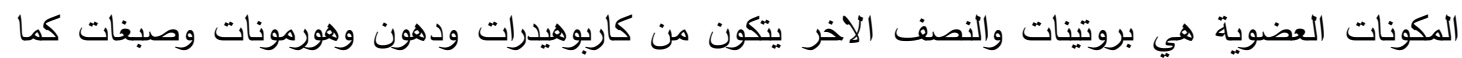
يحتوي على الالكتروليتات والعناصر المعدنية[21].

\section{Materials and Methods المواد وطرائق العمل}

العينة: جمعت عينات السائل الأمنيوني بحجم (220) مل من نساء الحوامل الاصحاء ظاهريا خلال فترة ما بين

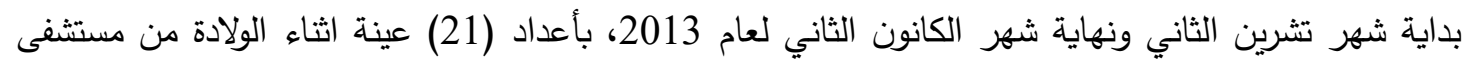

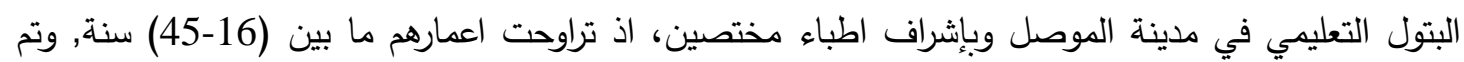
اخذ السائل الأمنيوني مباشرة واجريت له عملية الطرد المركزي عند سرعة 3500 x gلمدة (30) دقيقة للحصول على السائل بشكل رائق الذي استخدم لإجراء خطوات التتقية عليه بشكل مباشر .

\section{تقدير فعالية إنزيم برولايديز Determination of prolidase activity} تم تقدير فعالية إنزيم برولايديز حسب الطريقة المتبعة من قبل الباحث Myara واخديز

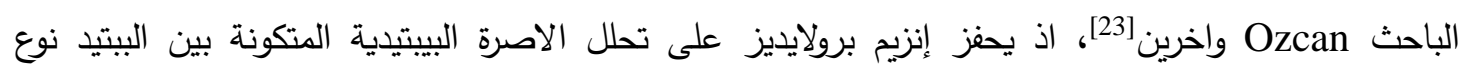
كلايسين -برولين (Gly-Pro) ليتحرر البرولين (كما موضح في المعادلة الاتية) الذي يتم تقديره باستعمال تفاعل الننهايدرين [24].<smiles>CCCN1C(C(=O)O)CCCN1C(=O)CNCC(=O)O</smiles>

تحضير الكواشف Preparation of reagents 1) محلول العمل Working solution: ويحتوي على ترس-حامض الهيدروكلوريك المنظم بتركيز 50 ملي مول/ لتر عند أس هيدروجيني 7.8 وكلوتاثايون بتركيز 1 ملي مول /لتر وكلوريد المنغنيز بتركيز 5 ملي

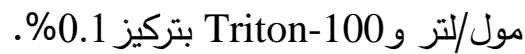
2) محلول مادة الاساس: ويتكون من مركب كلايسين - برولين (Gly-Pro) بتركيز 44 ملي مول/لتر • 3) محلول الكلوتاثايون بتركيز 29.93 ملي مول.

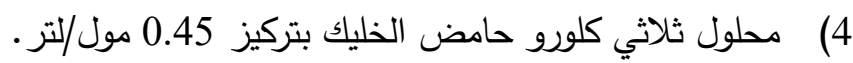


Procedure طريقة العمل تم وضع طريقة العمل لتقدير فعالية إنزيم برولايديز كما في الجدول الآتي:

\begin{tabular}{|c|c|c|}
\hline $\begin{array}{c}\text { محلول الاختبار } \\
\text { Test solution }\end{array}$ & $\begin{array}{c}\text { محلول البلانك } \\
\text { Blank solution }\end{array}$ & 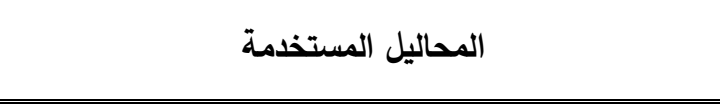 \\
\hline $1 \mathrm{~mL}$ & $1 \mathrm{~mL}$ & محلول العمل Working solution \\
\hline $200 \mu \mathrm{L}$ & - & السائل الأمنيوني Amniotic fluid \\
\hline- & $200 \mu \mathrm{L}$ & Dاء مقطر D.W \\
\hline \multicolumn{3}{|c|}{ مزج وحضن لمدة ثلاث ساعات عند 37 درجة مئوية } \\
\hline $200 \mu \mathrm{L}$ & $200 \mu \mathrm{L}$ & محلول مادة الاساس بتركيز 44 ملي مول/لتر. \\
\hline \multicolumn{3}{|c|}{ مزج وحضن في الحمام المائي لمدة 30 دقائق عند 37 درجة مئوية } \\
\hline $1 \mathrm{~mL}$ & $1 \mathrm{~mL}$ & محلول ثلاثي كلورو حامض الخليك بتركيز 0.45 مول /لتر \\
\hline
\end{tabular}

مزجت الأنابيب ووضعت في جهاز الطرد المركزي عند

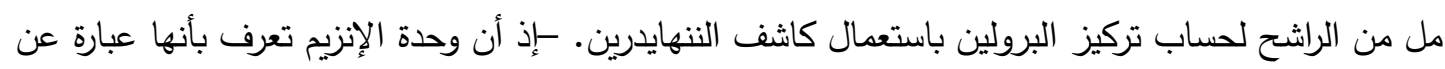
كمية الإنزيم التي تحول مايكرومول واحد من مادة الاساس كلايسين - برولين الى برولين لكل دقيقة لكل مليلتر تحت الظروف المحددة للقياس.

خطوات عزل إنزيم برولايديز من السائل الأمنيوني ودراسته:

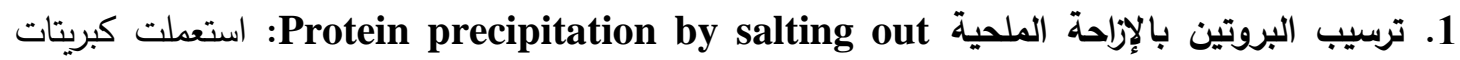

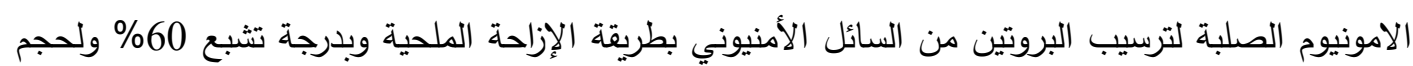

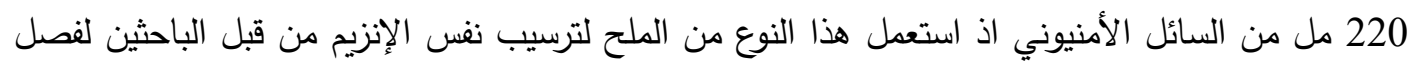

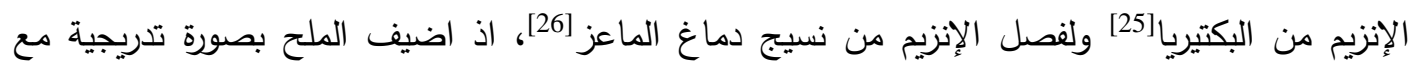
التحريك المستمر بالمرك المغناطيسي عند درجة حرارة 4ْم، ومن ثم ترك المحلول مدة 24 ساعة في الثلاجة لتترسب جميع البروتينات.

2. فصل الراسب بالطرد المركزي المبرد Separation of the precipitation by cooling centrifuge فصل الراسب عن السائل الرائق (الراشح) بجهاز الطرد المركزي المبرد بسرعة 9000 x g ولمدة 45 دقيقة، ثم أضيف الى الراسب المفصول اقل كمية من الماء المقطر، وبعد حساب حجم محلول الراسب البروتيني

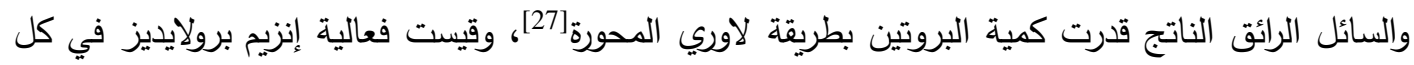

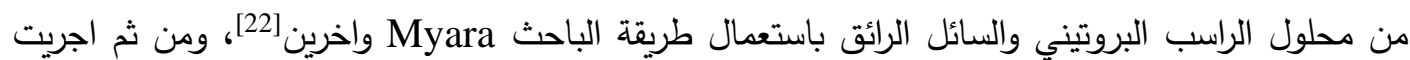
عليه الخطوة التالية من التنقية وهي عملية الفرز الغشائي.

3. الفرز الغشائي (الديلزة) Dialysis: أستخدم الراسب الذي كان بحجم (33.5 مل) والناتج من الخطوة (2) لإجراء عملية الفرز الغشائي عليه وباستعمال محلول بيكاربونات الامونيوم (NH4) مول[28] وذلك لتجنب تأثير دونان Donnan، اذ استعملت عملية الفرز الغشائي لإزالة كل البروتينات والببتيدات التي لها أوزان جزيئية اقل من 14000 دالتون وكذلك ايونات ملح كبريتات الامونيوم الناتج من

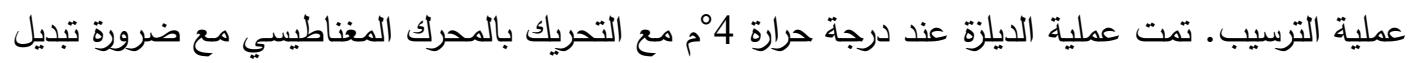


محلول بيكاربونات الامونيوم لثلاث مرات واستمرت العملية لمدة 24 ساعة. وبعد الانتهاء من عملية الفرز

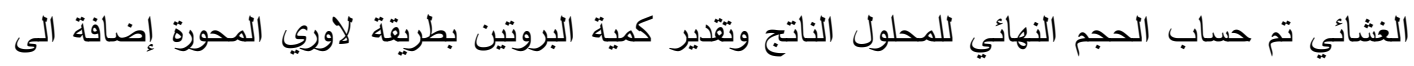
تقدير فعالية إنزيم برولايديز ثم حفظ المحلول في درجة -20 مُ لحين الاستعمال.

4. كروماتوغرافيا الترشيح الهلامي باستعمال سيفادكس G-50: استعمل عمود الفصل ذو الأبعاد (90×2) سم والذي يحتوي على هلام السيفادكس من نوع (Sephadex G-50) G-50) المخصص لفصل المركبات ذات الأوزان الجزئية لغاية 30 كيلو دالتون[29] وبالتالي التخلص من هن هذه المركبات التي لا نحتاجها في الدراسة الحالية. وبلغ ارتفاع الهلام في العمود 85 سم، تم حقن العمود بكمية 4 مل من المحلول الناتج من عملية الديلزة (الخطوة رقم 3) وقد ظهرت لدينا حزمة واحدة (الحزمة A) التي لديها أعلى فعالية نوعية للإنزيم

5. تقنية التجفيد Lyophilizer: تم تجفيد الحزمة البروتينية التي أظهرت فعالية نوعية عالية للإنزيم والناتجة من عمود الفصل نوع Sephadex G-50 الى ثلث حجمها، ثم أخذت العينة وحفظت عند درجة حرارة 20 20 حتى يتم تهيئتها للخطوة التالية.

6. كروماتوغرافيا الترشيح الهلامي باستعمال سيفادكس G-100: استعمل عمود الفصل ذو الأبعاد(90×2)سم والذي يحتوي على هلام السيفادكس من نوع Sephadex G-100) G-100). اذ بلغ ارتفاع الهلام في دوني العمود 85 سم، وحدد حجم الروغان للمواد القياسية التي حقنت في العمود لغرض تحديد صفات العمود وإيجاد منحني قياسي لتحديد الوزن الجزيئي التقريبي (للحزمة البروتينية ذات الفعالية العالية الناتجة من حقن

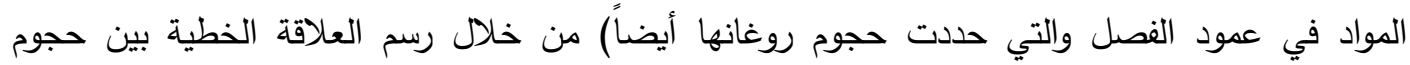
روغانها ولوغاريتم أوزانها الجزيئية المعلومة [30] فئ.

المواد والمحاليل المستعملة في اعمدة الفصل (سيفادكس G-50 وسيفادكس G-100): المحلول المنظم نوع ترس-حامض الهيدروكلوريك ذو أس هيدروجيني 8 وبتركيز 10 ملي مول/لتز ، المحلول البروتيني (للراسب)

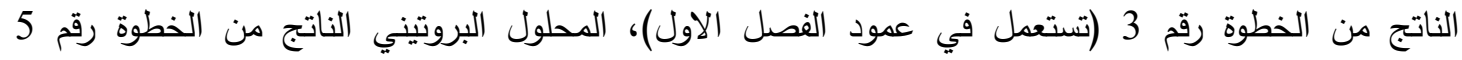

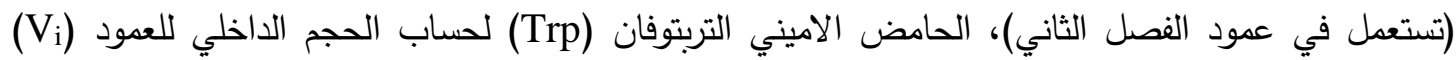

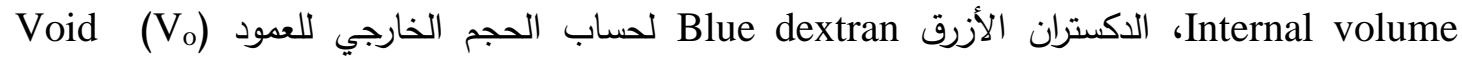
volume

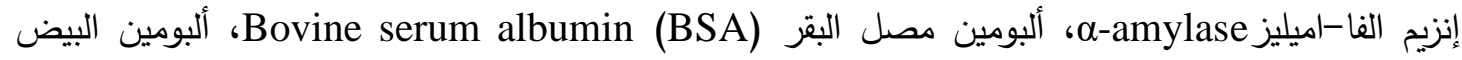
Egg albumin

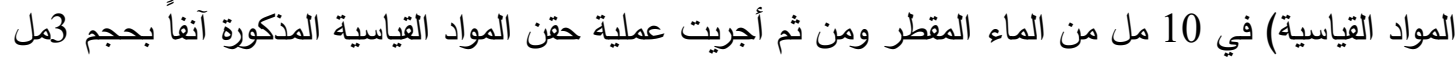

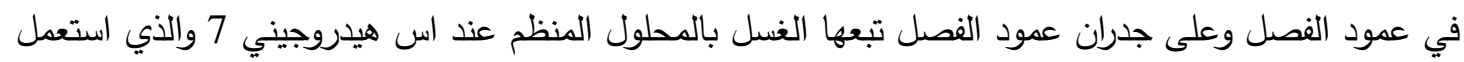

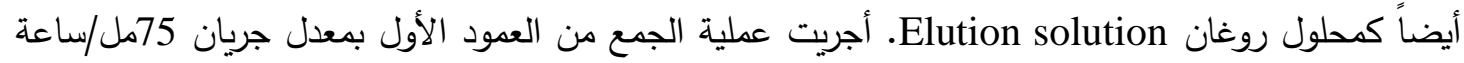
وبفاصل زمني مقداره ثلاث دقائق لكل جزء، اما للعمود الثاني فقد كانت عملية الجمع بمعدل جريان 62

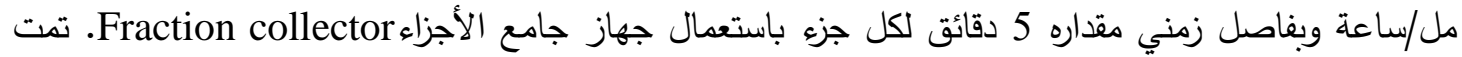

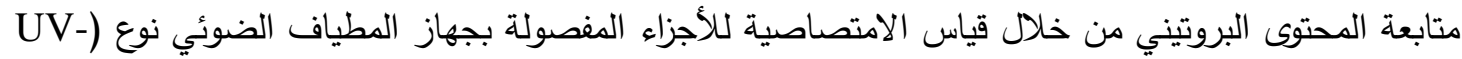
(Vis Spectrometer-PD 303UV 
في كل جزء من الأجزاء المفصولة باستعمال طريقة الباحث (Myara) واخرين [22]، ومن ثم جمعت الأجزاء البروتينية الحاوية على أعلى فعالية للإنزيم.

7. تقنية التجفيد Lyophilizer: تم تجفيد الحزمة البروتينية الناتجة ذات أعلى فعالية نوعية لإنزيم برولايديز

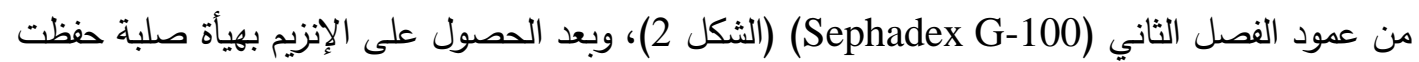

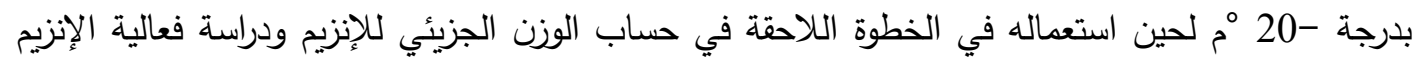

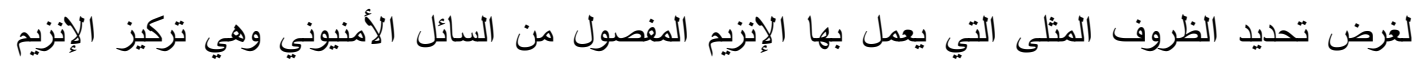

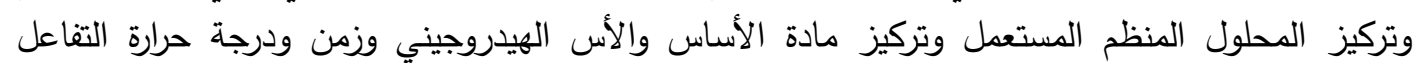

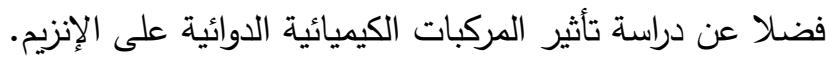

التأثير التثبطي او التنشيطي للمركبات الكيميائية الدوائية

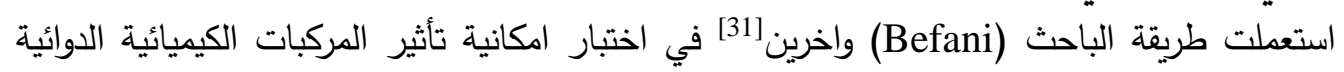

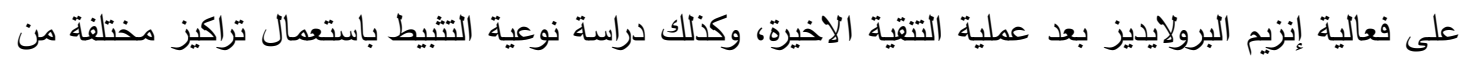
المواد الكيميائية على التفاعل الإنزيمي المحدد لقياس فعالية الإنزيم بعد تحديد الظروف المثلى عليه.

\section{النتائج والمناقثة}

تثير النتائج الموضحة في الجدول(1) الى إن الفعالية النوعية للإنزيم ارتفعت الى قئهة

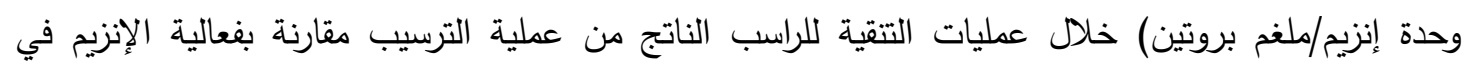

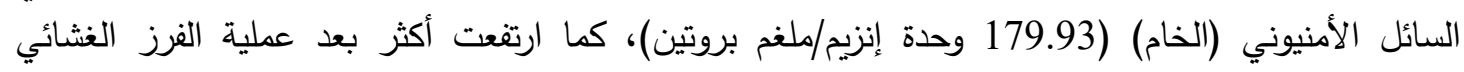

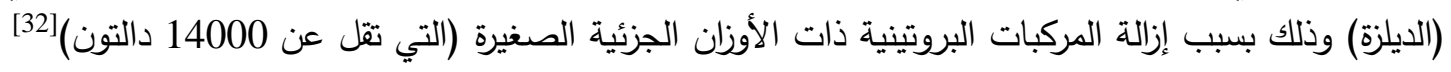

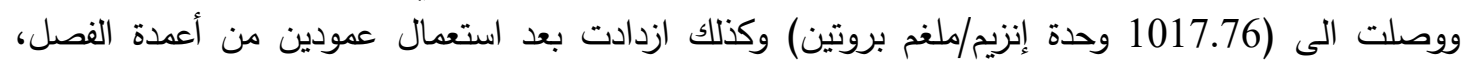

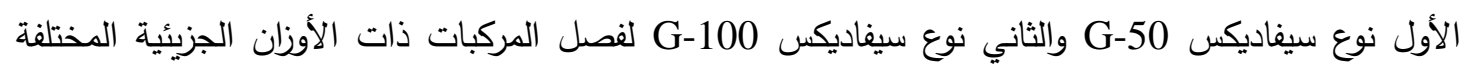

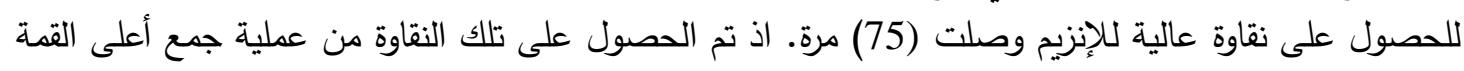
للإنزيم ذات الفعالية العالية والكمية القليلة للبروتين.

الجدول 1: خطوات تنقية إنزيم برولايديز من سائل الأمنيوني الإنسان.

\begin{tabular}{|c|c|c|c|c|c|c|c|}
\hline \% الاستعادم & | التنقية & ( الفعالية النوعية & 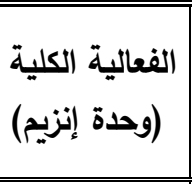 & \begin{tabular}{|c|} 
الفعالية للإنزيم \\
إنزيم/مل) \\
("وحدة \\
\end{tabular} & |تركيز البروتين & (مل) & خطوات التنقية \\
\hline 100 & 1 & 179.93 & 114400 & 520 & 2.89 & 220 & السائل الأمنيوني \\
\hline 62.4 & 3 & 518.73 & 71422 & 2132 & 4.11 & 33.5 & الترسيب بكبريتات الامونيوم 60\% \\
\hline 35.5 & 1 & 263.58 & 40565 & 213.5 & 0.81 & 190.0 & الراشح \\
\hline 62.2 & 6 & 1017.76 & 71177.5 & 2005 & 1.97 & 35.5 & الايلزة للراسب \\
\hline 55.8 & 17 & 3134.3 & 63840 & 2100 & 0.67 & 30.4 & الترشح الهلامي سيفادكس عمود الفتاتجة من القصل \\
\hline 37.6 & 75 & 13516.66 & 43064.1 & 2433 & 0.18 & 17.7 & الترشح الهلامي سيفادكس A الناتجة من عود الفصل \\
\hline
\end{tabular}

* وحدة الإنزيم: هي عبارة عن كمية الإنزيم التي تحول مايكرومول واحد من مادة الاساس (Gly-Pro) الى برولين لكل دقيقة لكل

مليلتر تحت الظروف المحددة للقياس. 
كروماتوغرافيا الترشيح الهلامي:

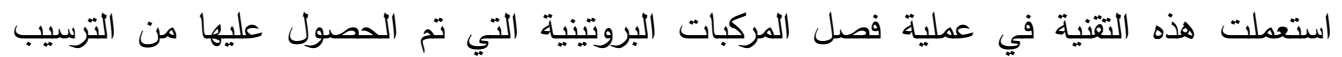

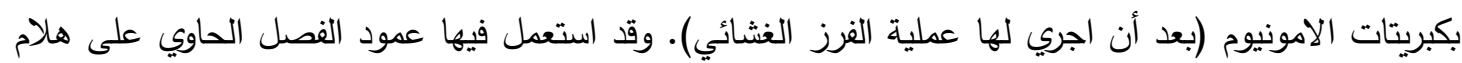

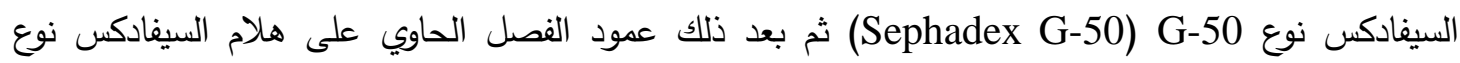

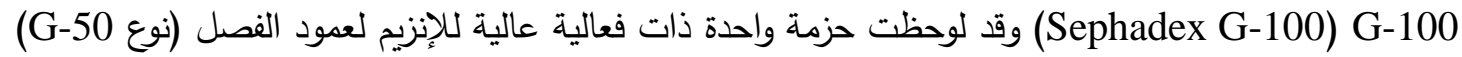
(الثكل 1) وكانت القمة عند حجم روغان 164.7مل (وان حجم الروغان لبداية ظهور حزمة فئة فعالية الانزيم

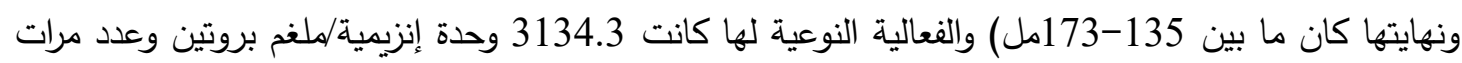

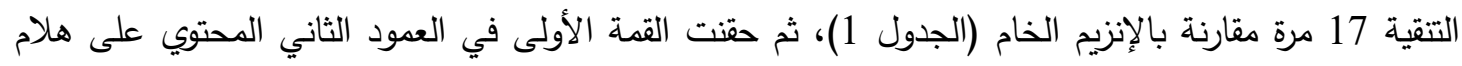

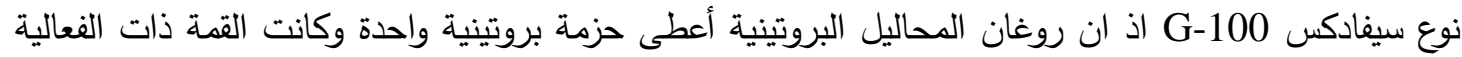

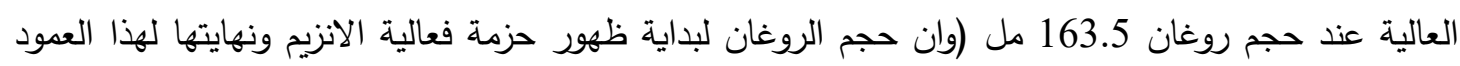

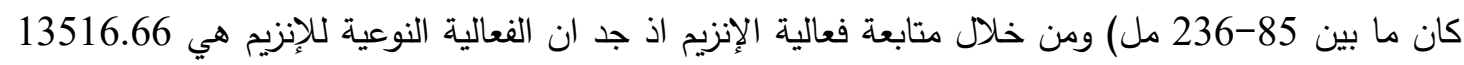

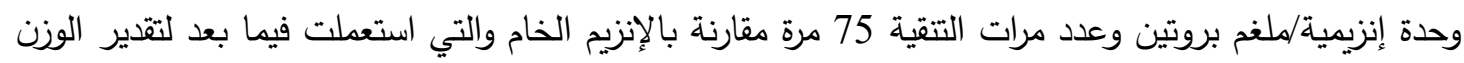

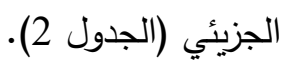

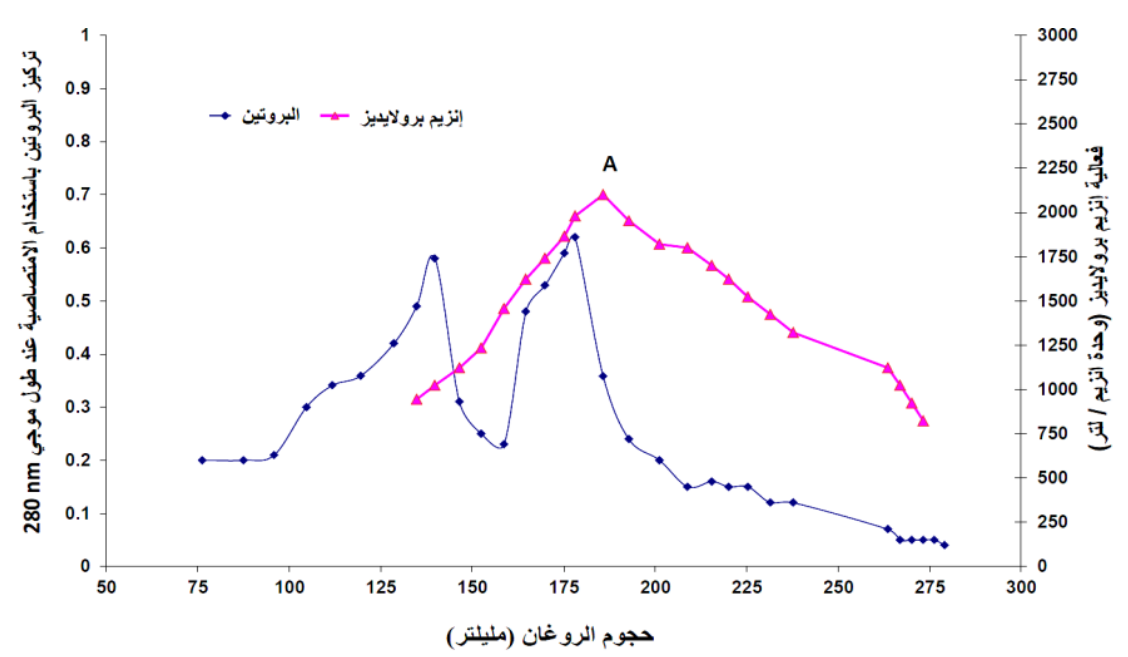

الثكل 1: المظهر الجانبي لروغان الحزمة البروتينية لإنزيم برولايديز الناتجة من عمود الفصل نوع Sephadex G-50 الثناني

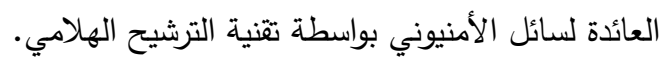

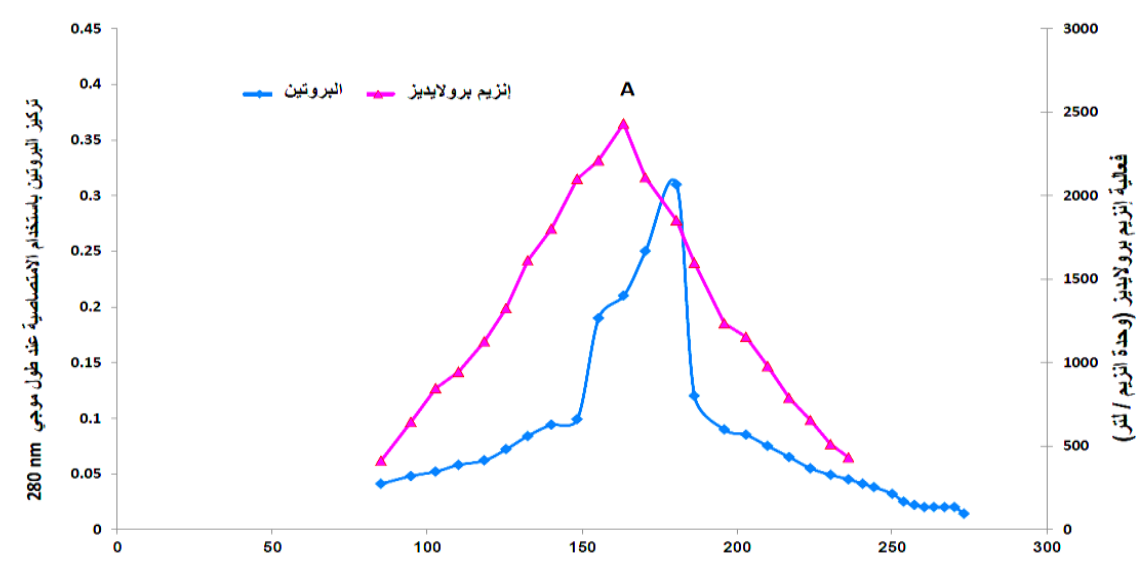

حجوم الروضان (مليلتر)

Sephadex G- الثكل 2: المظهر الجانبي يبين روغان الحزمة البروتينية لإنزيم برولايديز الناتجة من عمود الفصل 100 والعائدة لسائل الأمنيوني بواسطة تقنية الترشيح الهلامي. 


\section{تقدير الوزن الجزيئي التقريبي لإنزيم البرولايديز بتقنية الترشيح الهلامي :}

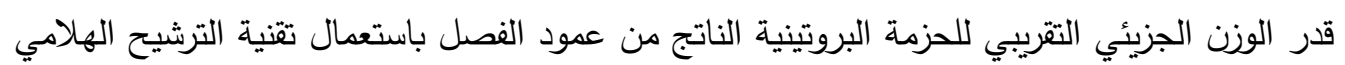

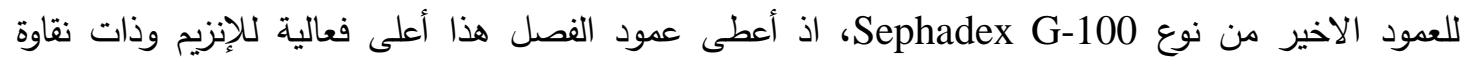
وصلت الى (75) مرة لذلك تم استعمالها في تقدير الوزن الجزئي للإنزيم من خلال إمرار عدد من المركبات معلومة الوزن الجزيئي والتي تتراوح أوزانها الجزيئية بين (204 -

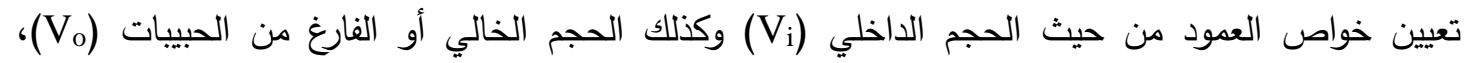

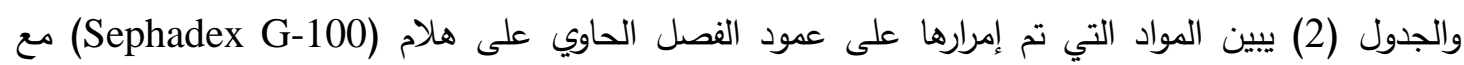

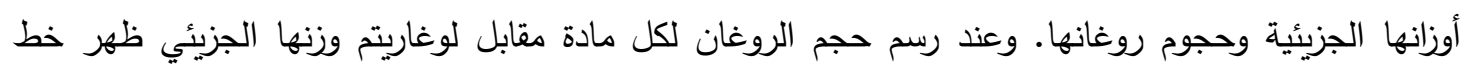

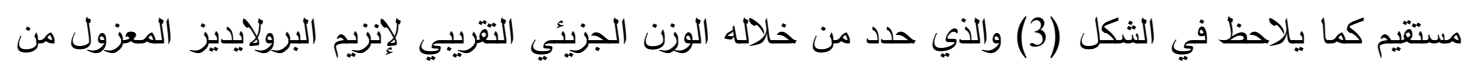

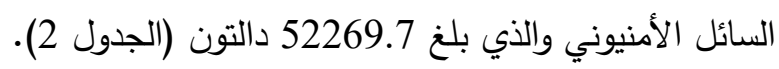
ان إنزيم برولايديز اجريت له عمليات تتقيته من مصادر مختلفة لأنسجة مختلفة من الانسان الأنس

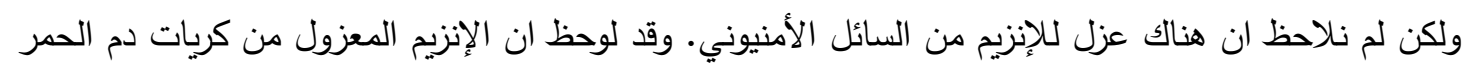

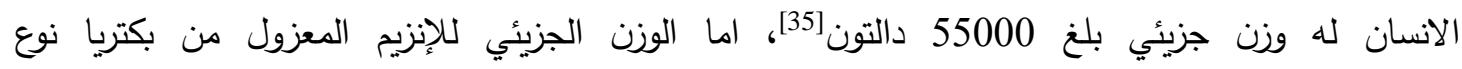
Aureobacterium esteraromaticum

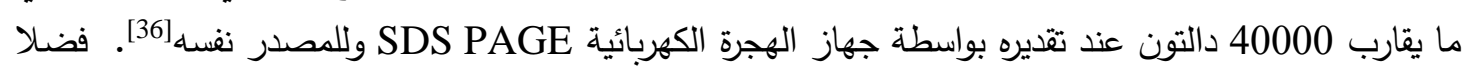
عن ذلك فقد لوحظ ان هناك قمتين عند فصل إنزيم البرولايديز من بروستات الانسان، وان للإنزيم ايزومرين ولهم

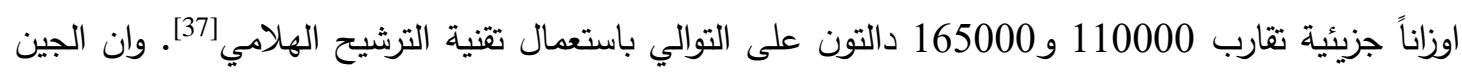

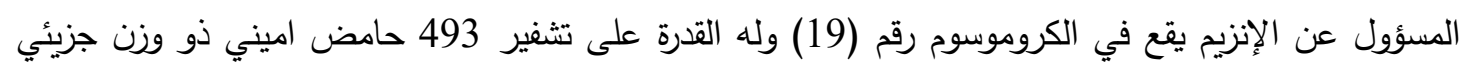

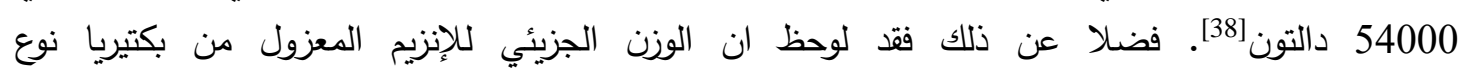
Xanthomonas maltophilia

الجدول 2: الاوزان الجزيئية وحجوم روغان المواد القياسية المستعلة في تقنية الترشيح الهلامي باستعمال هلام نوع

\section{. Sephadex G-100}

\begin{tabular}{|c|c|c|}
\hline حجم الروغان & الوزن الجزيئي & أسم المادة القياسية \\
\hline 99 & 2000000 & الدكستران الأزرق Blue dextran (الحجم الخالي Von ) \\
\hline 126 & 100000 & هexokinase هيكسوكاينيز \\
\hline 160 & 67000 & ألبومين مصل البقرBovine serum albumin \\
\hline 172 & 58000 & الفا-|ميليز م- amylase \\
\hline 216 & 45000 & Egg albumin ألبومين البيض \\
\hline 244 & 36000 & البيسين Pepsin \\
\hline 280 & 21000 & Papain الباباين \\
\hline 437 & 204 & التربتوفان Tryptophan (الحجم الداخلي Vi) \\
\hline$* 163.5$ & 52269.7 & المجهول (القعة A ذات فعالية عالية) \\
\hline
\end{tabular}

* أخذت هذه القيمة من الثكل رقم (2) الذي يظهر فيه حجم روغان القمة المفصولة للإننزيم من سائل الأمنيوني بواسطة تقنية

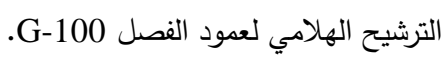




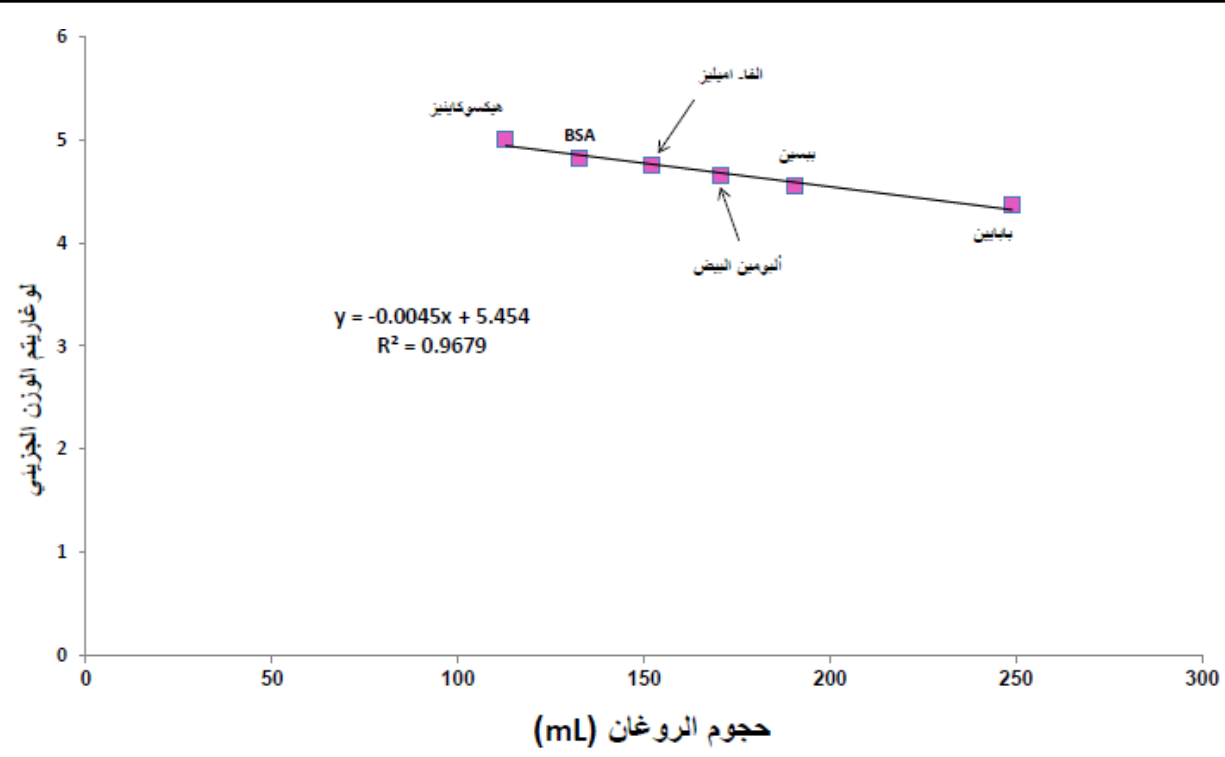

Sephadex G- الثكل 3: المنحني القياسي لتحديد الوزن الجزيئي بتقنية الترشيح الهلامي باستعمال عمود الفصل نوع

دراسة العوامل المؤثرة على فعالية إنزيم برولايديز المعزول من السائل الأمنيوني: تكون التفاعلات التي تحفزها الإنزيمات حساسة للظروف الخارجية مثل كل التفاعلات الكيميائية الاخرى, وهكذا فان تركيز الإنزيم وتركيز مادة الأساس ودرجة الحرارة والأس الهيدروجيني (pH) تؤثر على معدل سرعة التفاعل الإنزيمي لان جميع هذه العوامل تؤثر على الموقع الفعال للإنزيم وتؤثر على تكوين معقد الإنزيم

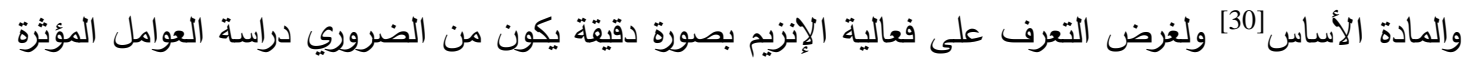

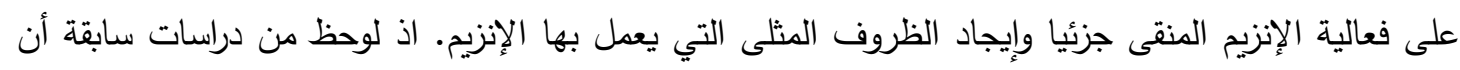
إنزيمات البرولايديز تختلف بثكل رئيس حسب خصوصية مواد الاساس واحتياجها الى الدعادن ودرجة الحرارة

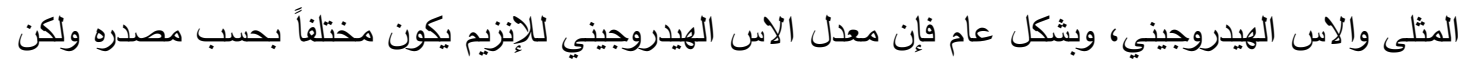
يمكن ان يكون ما بين 6-8 وان القيمة المثلى للإنزيم تعتمد على المصدر الذي عالِي عزل منه الإنزيم، وان دان درجة الحرارة المثلى لها يمكن ان تكون ما بين 35-55 مُ للإنزيم البرولايديز المشتق من مصادر ذاندئ ذات الحرارة المعتدلة

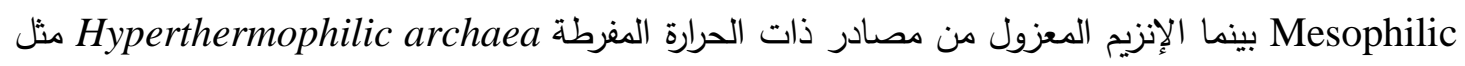

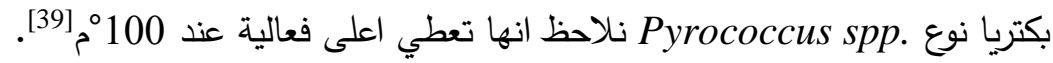

1. تأثير تركيز الإنزيم: تم تقدير فعالية إنزيم برولايديز بوجود تراكيز مختلفة من الإنزيم المنقى جزئياً من

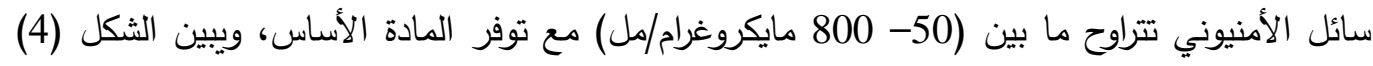

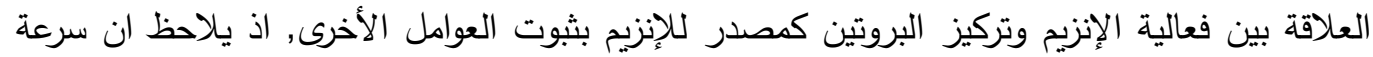
التقاعل الإنزيمي تزداد بزيادة تركيز الإنزيم المنقى الى حد 50 مايكروغرام/مل ثم انخفض ولثن وعليه اعتمد

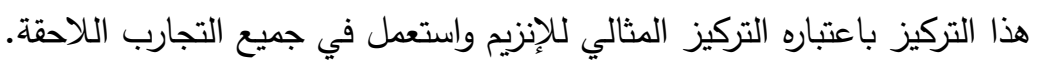
2. تأثير تركيز المحلول المنظم المستعمل: تمتاز المحاليل المنظمة بكونها مقاومة للتغير في تركيز ايون الهيدروجين عند اضافة كميات قليلة من حامض او قاعدة الى المحلول وتعد معرفة تركيز المحلول المنظم ضرورية لقياس فعالية الإنزيمات, وتم استعمال تراكيز مختلفة من المحلول المنظم تتراوح ما بين

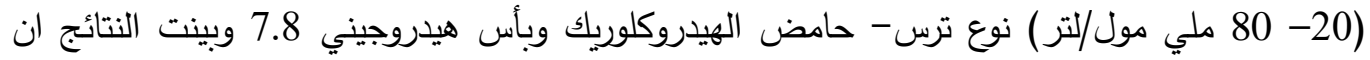


الفعالية المثالية للإنزيم برولايديز المعزول كانت عند تركيز (60 ملي مول/لتر) من المحلول المنظم وكما

مبين في الشكل (5).

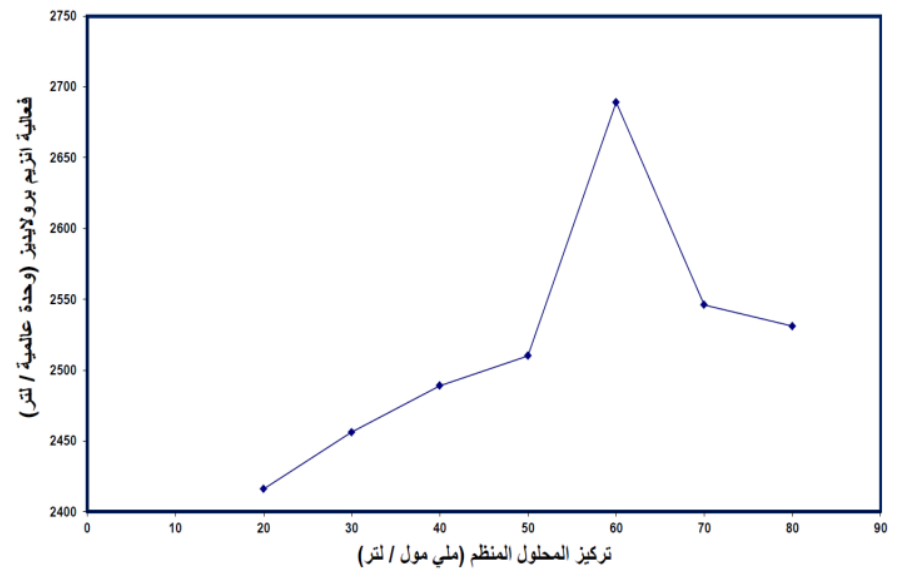

الثكل 5: تأثير التراكيز المختلفة للمحلول المنظم على فعالية

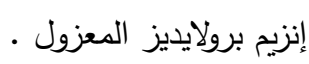

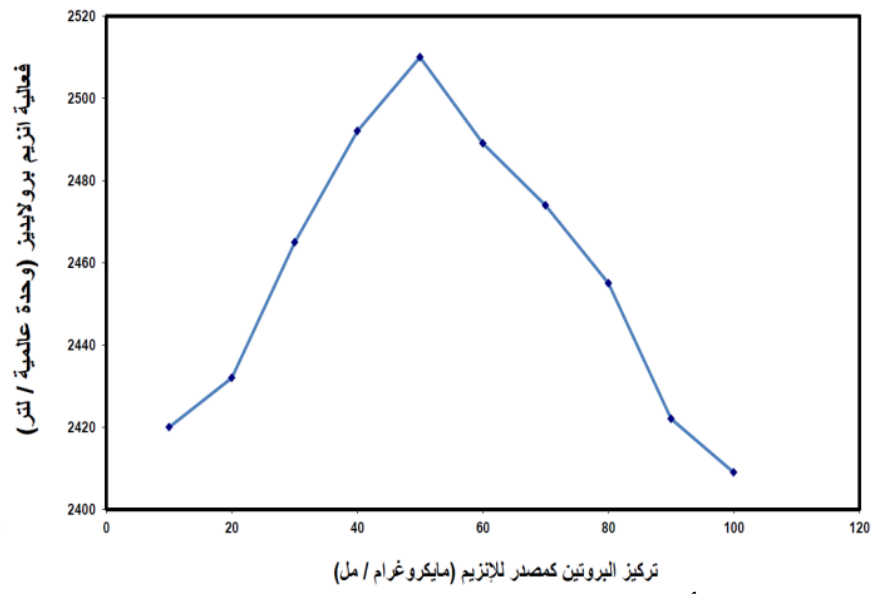

الثكل 4: تأثير التراكيز المختلفة من البروتين المنقى كمصدر

$$
\text { للإنزيم على الفعالية. }
$$

3. تأثير الأس الهيدروجيني (pH): تم تقدير فعالية إنزيم برولايديز في محلول المنظم نوع ترس- حامض

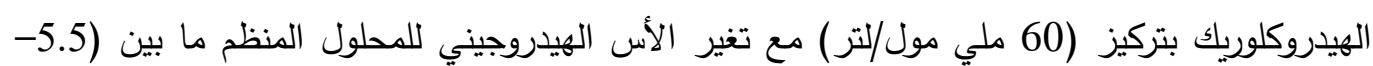

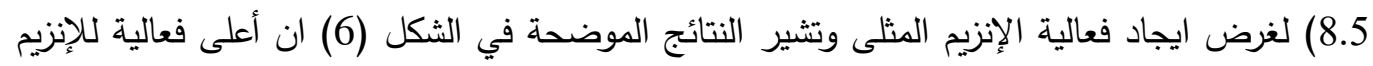

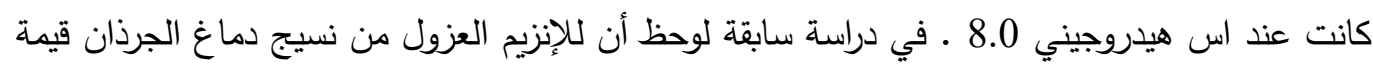

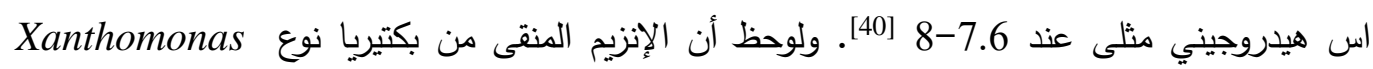
maltophilia

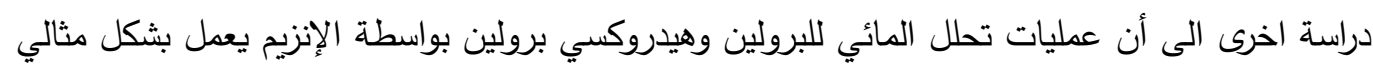
عند اس هيدروجيني 9 للإنزيم المفصول من بكتريا نوع Aureobacterium esteraromaticum

4. تأثير زمن التفاعل: تمت دراسة زمن التفاعل ما بين (0- 40 دقيقة) لاختيار الفترة الزمنية المثلى لعمل

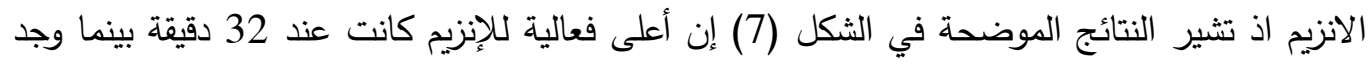

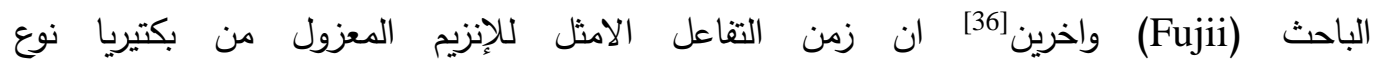
Aureobacterium esteraromaticum

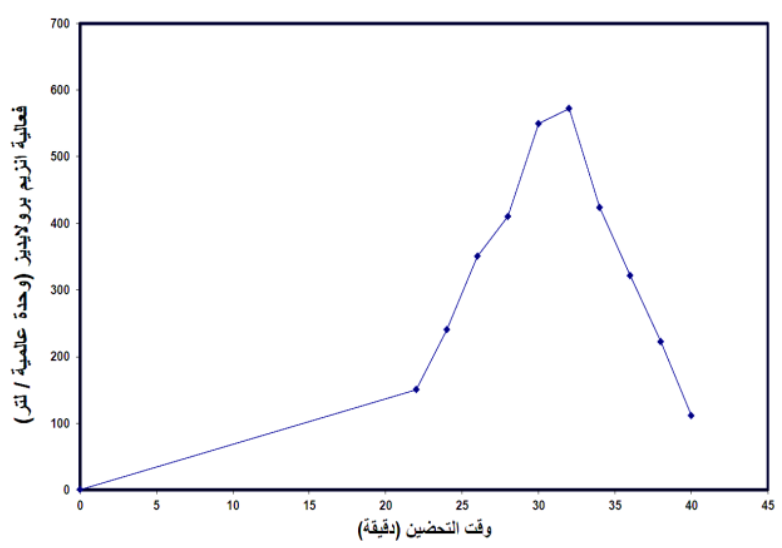

الثكل 7: تأثير زمن التفاعل على فعالية إنزيم

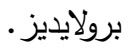

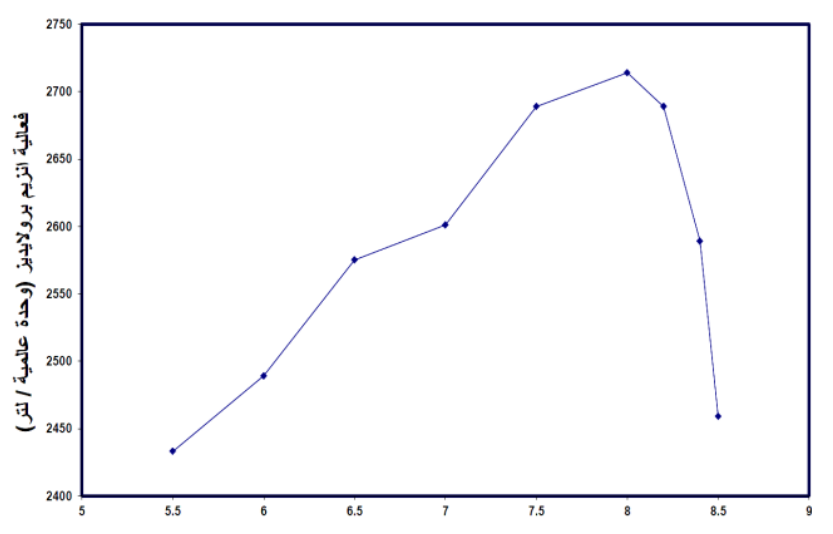

الثكل 6: تأثير الأس الهيدروجيني الثيني على فعالية

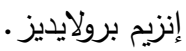




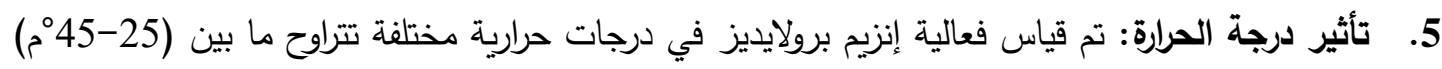

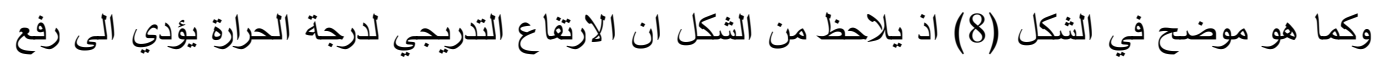

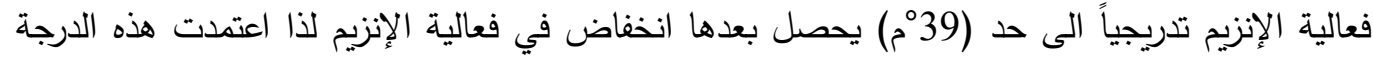
كدرجة الحرارة المثلى للإنزيم في التجارب اللاحقة. اذ ان التفاعلات التي تحفزها الإنزيمات تتأثر بدرجات

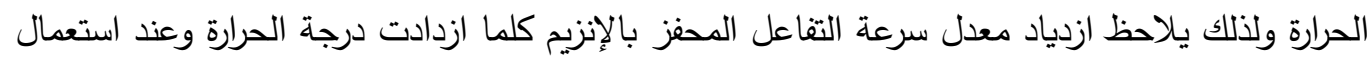
درجات حرارة اعلى من درجة الحرارة المثلى (وهي درجة الحرارة التي يبدي عندها الإنزيم اعلى فعالية له)

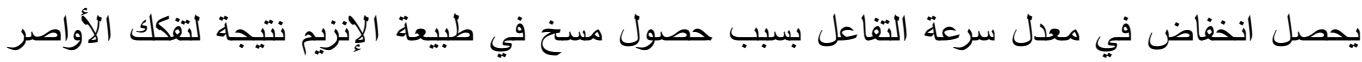
الهيدروجينية والقوى الأخرى المسؤولة عن المحافظة على التركيب الثلاثي للبروتين ومن ثم فقدان فئه

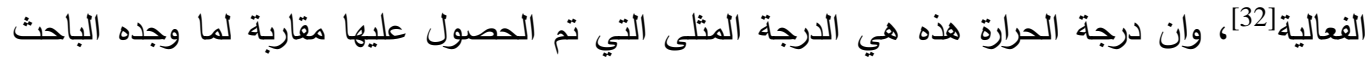

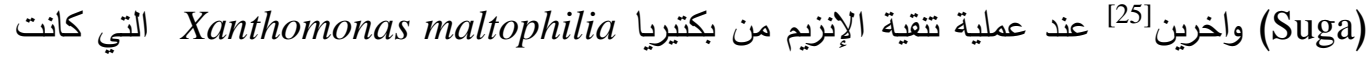

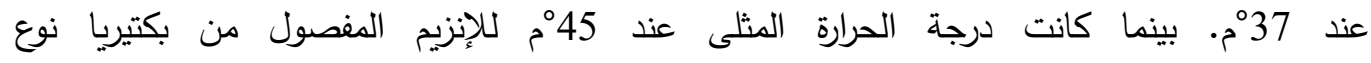
. ${ }^{[36]}$ Aureobacterium esteraromaticum

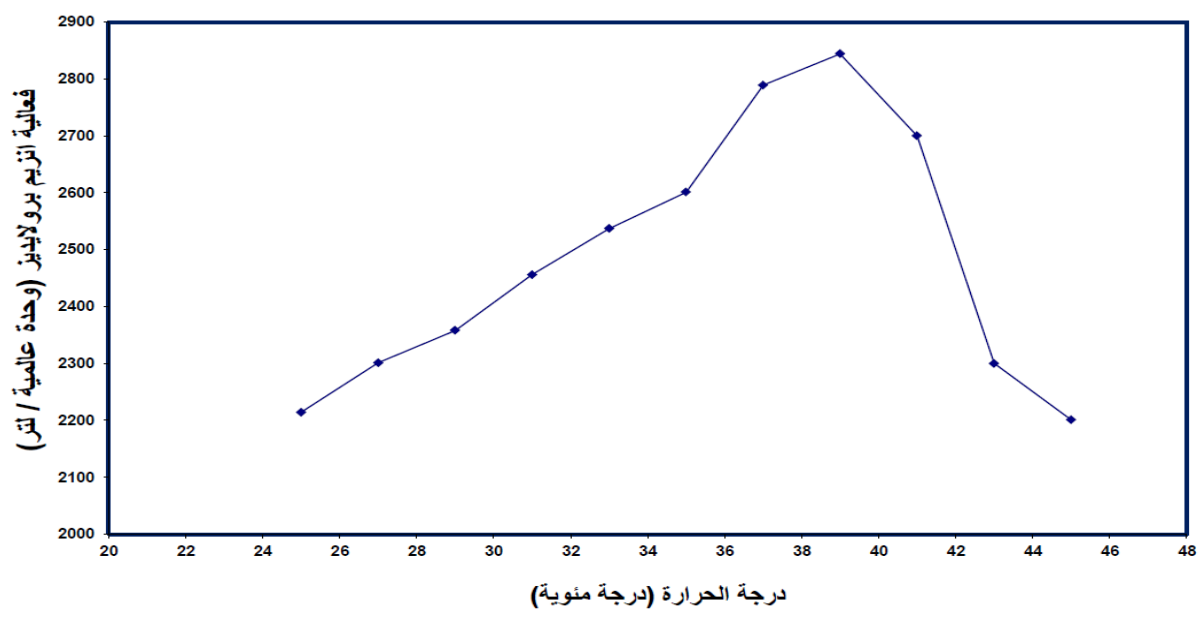

الشكل 8: تأثير درجة الحرارة على فعالية إنزيم برولايديز •

6. تأثير تركيز مادة الأساس من البيتيد نوع كلايسين - برولين: يطلق على أعلى سرعة للتفاعل الإنزيمي

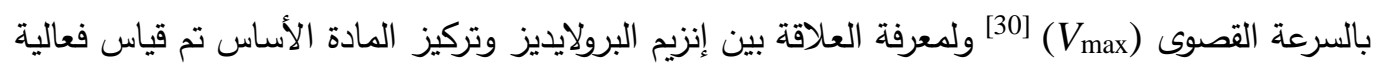

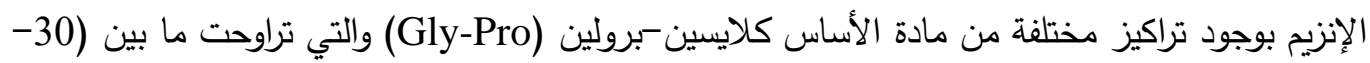

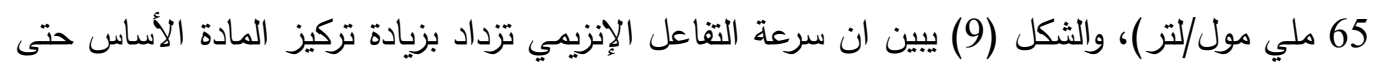

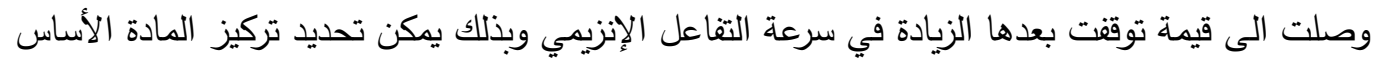

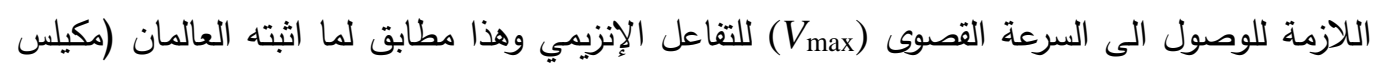

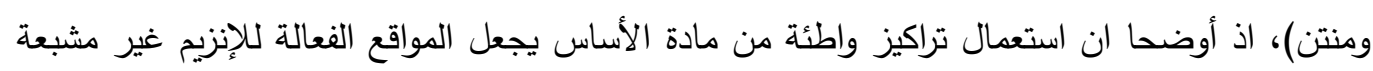

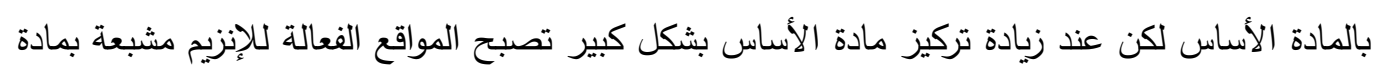

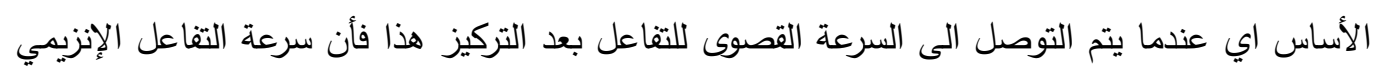

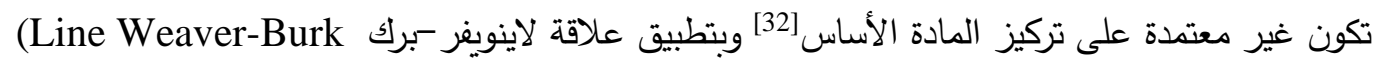

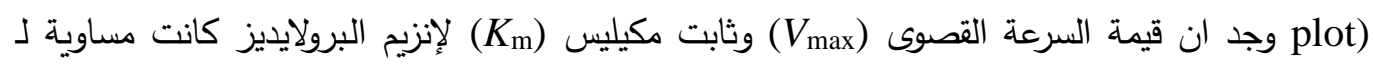


3448.2 وحدة إنزيم/لتز و10 ملي مول/تتر على التوالي وكما هو موضح في الثكل (9). لوحظ في

دراسات سابقة ان قيمة ثابت مكيليس (K) 178 مايكرومول وقيمة السرعة القصوى (V)

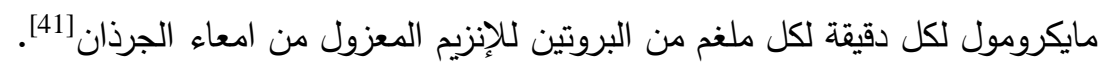

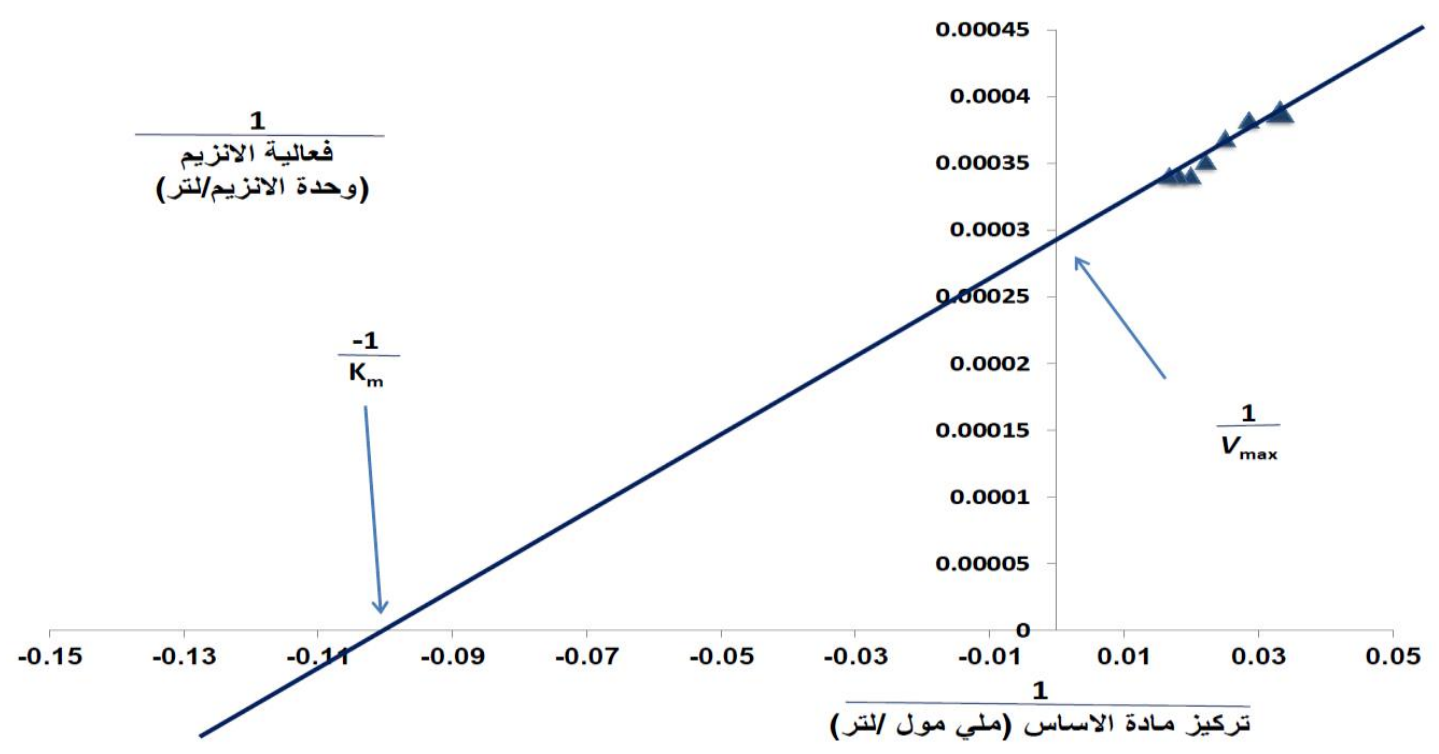

الثكل 9: رسم لاينويفر - برك لتحديد قيمتي السرعة القصوى(

7. تأثير المركبات الكيميائية الدوائية على فعالية إنزيم برولايديز:

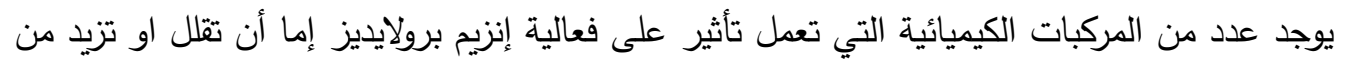

سرعة التقاعل الإنزيمي وقد تم استعمال عدد من المركبات الكيميائية الدوائية لمعرفة تأثيرها على فعالية الإنزيم المعزول من السائل الأمنيوني، واستعملت الظروف المثلى المحددة مسبقا لدراسة تأثير المركبات الكيميائية المختلفة على فعالية الإنزيم فقد لوحظ ان لظروف الإنزيم السابقة الذكر من الاس الهيدروجيني وغيرها التأثير

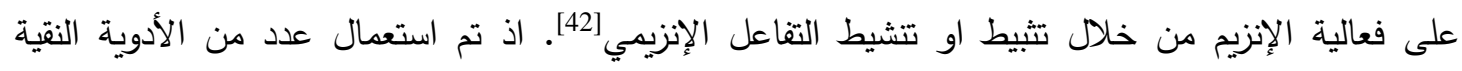
المحددة (لا تحوي اي مضافات عليها) واستحصلت من الشركة العامة لصناعة الأدوية, ومن شركة الحكماء لصناعة الأدوية والمستلزمات الطبية في محافظة نينوى لمعرفة تأثيرها على فعالية إنزيم برولايديز، ويوضح

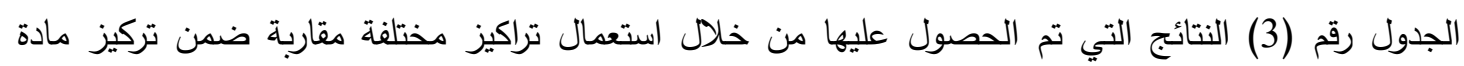
الاساس التي تم الحصول عليها عند تحديد الظروف المثلى للإنزيم وهي (5 و10 و15 ملي مول/تلتر) لجميع

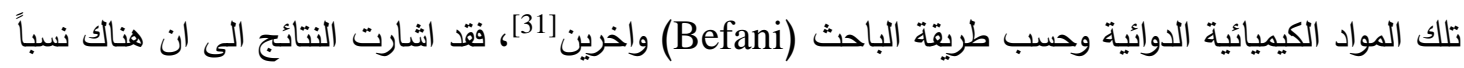

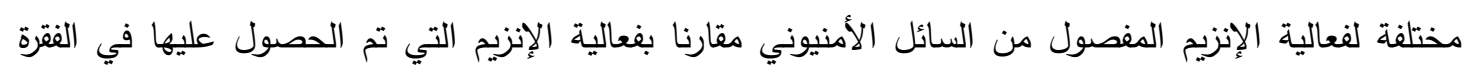

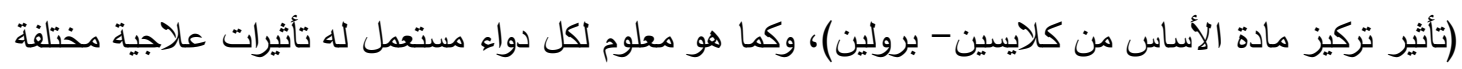

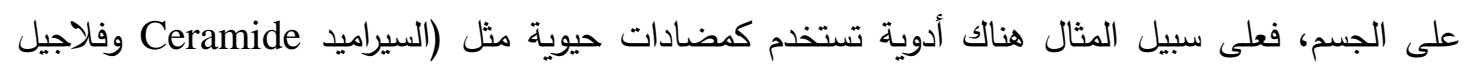
(Flagyl الباراسيتامول وبسيدوفيريدين Psedophedrine وثايوفلين اللامائي Theophyllin anhydrous الذي يعد من مجموعة الزانثات Xanthes ويثبط الناقلات العصبية ويستعمل في علاج الربو والكلورفينيرامين ماليت Chlorpheniramine-maleate وهو مضاد الهستامين يستعمل لحالات تحسس الجهاز التتفسي العلوي التي ولئي 
تتضمن الجيوب الانفية[43] والداي فينهايدرامين - هايدروكلورايد في Diphenhydramine-HCl الذي يستعمل

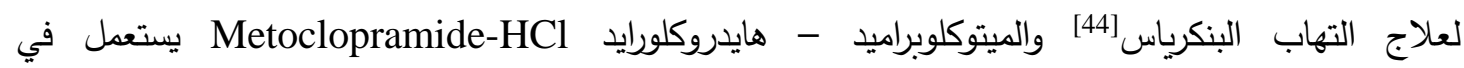
الاضطرابات الهضمية لتخفيف ومنع الغثيان والاقياء بعد العمليات الجراحية[46]، كما تم دراسة تأثير الدكساميثازون وهو دواء ينتمي الى فئة الأدوية الهورمونية الستيرويدية وهو مضاد للالتهابات [52]. اوضحت النتائج في الجدول رقم (3) الى ان هناك تثبيط لفعالية الانزيم عند استعمال المركبات الكيميائية الدوائية المختارة وبنسب مختلفة عند استعمال التراكيز (5، 10، 15 ملي مول/لتر ) مقارنة مع الفعالية القياسية الاخيرة للإنزيم وهي 3448.2 وحدة عالمية /لتر •

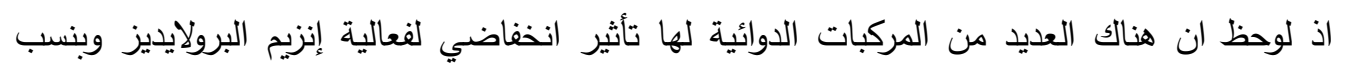

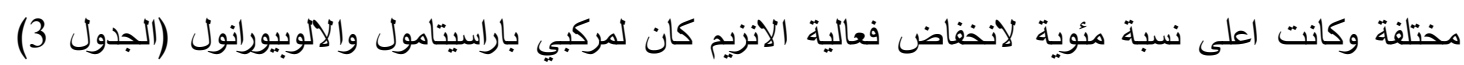
وهذا يمكن الاستفادة منه في تقليل من حدوث بعض الامراض او مضاعفاتها التي تزيد من تليف الانسجة مثل بل تليف الكبد او تقليل من حدوث عملية تصلب الشرايين ولكن بالمقابل يمكن ان يؤثر على الوظائف الحيوية

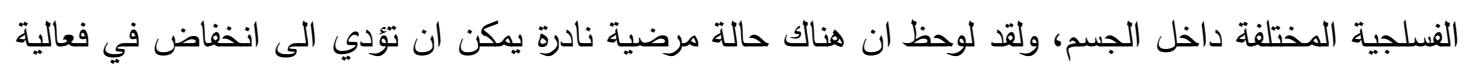
الإنزيم في الجسم والذي من المكن ان يؤثر على النسيج الرابط ومن اعراضه الآفات الجلدية والتخلف العقلي والتهابات الجهاز التنفسي المتكررة وقد لوحظ ان الإنزيم المنقى من مصادر مختلفة من المككن ان يحل محل النحل بعض العلاجات[16] فضلا عن ذلك فأن تجنب بعض الادوية التي يمكن ان تزيد من انخفاض فعالية الانزيم

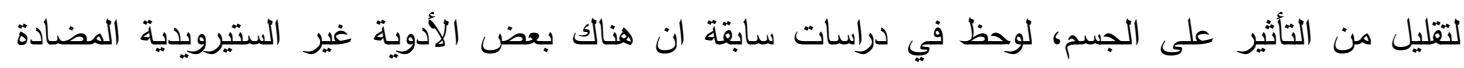

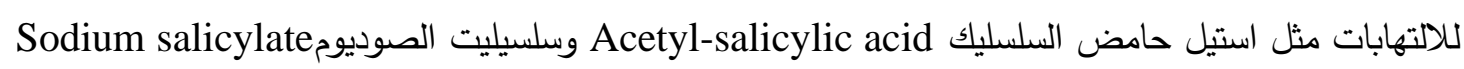
وفينايل بيوتازون Indomethacin لها دور في تثبيط العمليات الايضية

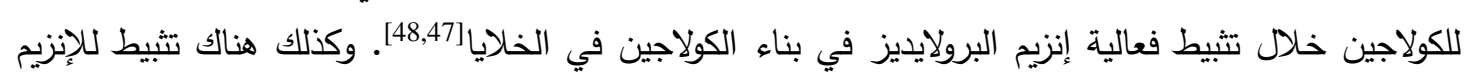

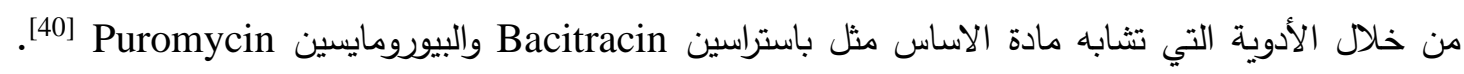
وفي دراسة اخرى لوحظ ان الكلورافينيكول يعمل على التثبيط بشكل قليل لعملية بناء الكولاجين وبالتالي تقليل من التاني

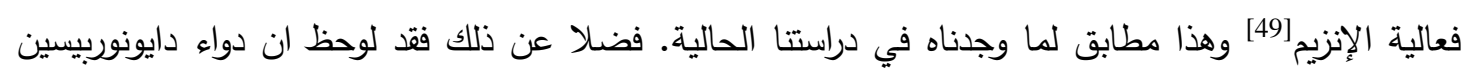
Daunorubicin يعمل على التثبيط من فعالية إنزيم البرولايديز [50].

الجدول 3: تأثير بعض المركبات الكيميائية الدوائية على فعالية إنزيم برولايديز .

\begin{tabular}{|c|c|c|c|c|c|}
\hline 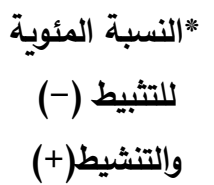 & فعالية الإنزيم & تركيز المركب & $\begin{array}{c}\text { للمركبات الكيميائية الكيميائي } \\
\text { الدوائية }\end{array}$ & المركبات الكيميائية الدوائية & 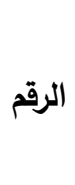 \\
\hline-50.08 & 1721.2 & $\overline{5}$ & & & \\
\hline-50.77 & 1697.3 & 10 & & سيراميد يفضل تنشيط & 1 \\
\hline-53.57 & 1600.8 & 15 & & Ceramide & \\
\hline-48.85 & 1763.5 & 5 & & & \\
\hline-53.59 & 1600.23 & 10 & & ميتوكلوبراميا & 2 \\
\hline-56.47 & 1500.8 & 15 & & Metoclopramide & \\
\hline-46.99 & 1827.6 & 5 & & & \\
\hline-48.21 & 1785.7 & 10 & & بيسيدوفيدرين & 3 \\
\hline-49.38 & 1745.3 & 15 & & Pseudoephedrine & \\
\hline
\end{tabular}




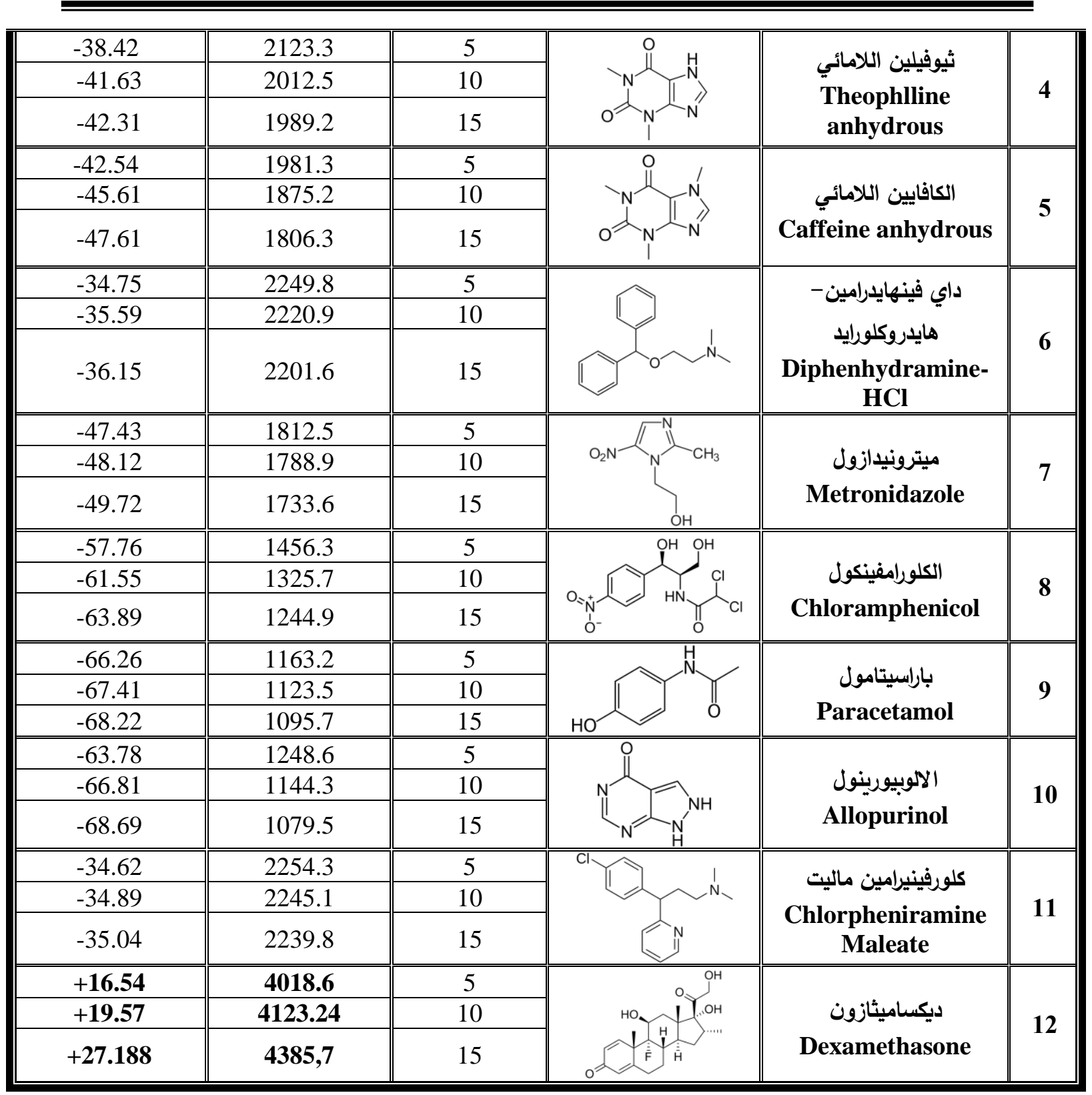

* علما ان الفعالية القياسية للإنزيم بدون تثبيط (Control) هي 3448.2 وحدة عالمية /تزر.

ومن جانب اخر فقد لوحظ ان هناك زيادة في نشاط فعالية الإنزيم اذ وصلت النسبة المئوي لتتشيط

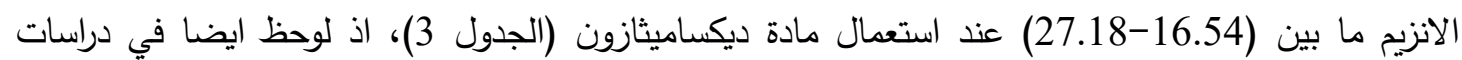
سابقة ان هناك بعض الأدوية لها تتشيط في فعالية إنزيم البرولايديز مثل الدواء الكيميائي نوع الميليفالين Melphalan اشارت بعض النتائج السابقة ان لمركب الهيدرازين القدرة على تحفيز بناء الكولاجين من خلال تحفيزه لإنزيم

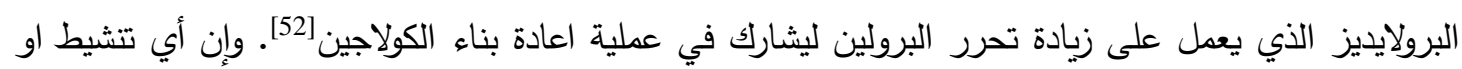
تثبيط للإنزيم هو يكون من خلال التأثير على الموقع الفعال لإنزيم البرولايديز من خلال التأثير على على الأحماض الامينية الهستيدين وحامض كلوتاميك وحامض الاسبارتيك التي تشارك في زيادة استقرار الموقع الفعال وفعاليته [14]. 
ان إنزيم البرولايديز ضعيف في فعاليته التحليلية المائية لمركبات الفسفور العضوية السامة لهذا فأن ايجاد الإنزيم بفعالية عالية جدا ضروري لدعم عملية تحلل تلك المركبات السامة من العوامل العصبية الكيميائية والمبيدات الحشرية مثل مركب Diisopropyl fluorophosphates (DFP) او المركبات ذات التعات التأثيرات العصبية التي تستعمل في الحروب والمثبطة لإنزيم كولين أستريز [53)، ولهذا كان من الضروري ان نعمل على النى

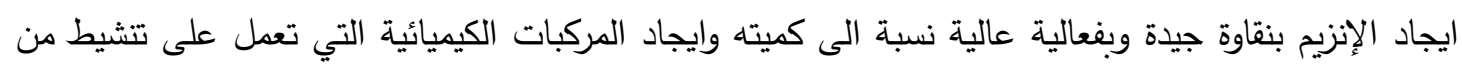
المركبات الدوائية، فضلا عن ذلك فانه يمكن ان يتم تطوير عملية تكوين الانزيم من خلال تقنية الهندسة الوراثية لبإنزيم [53]

8

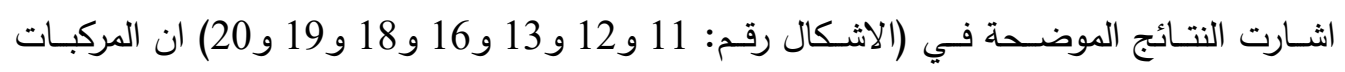

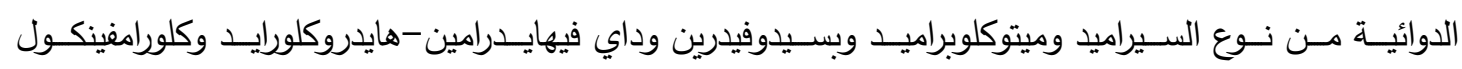

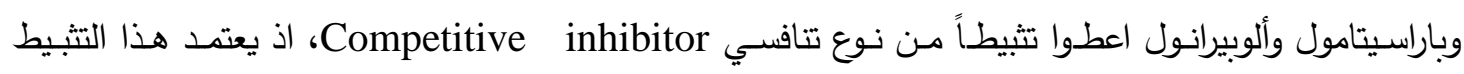

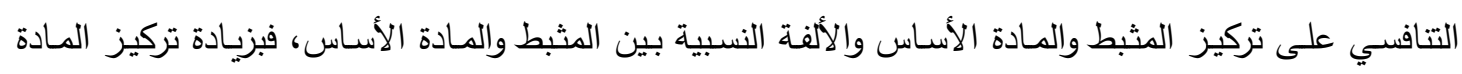

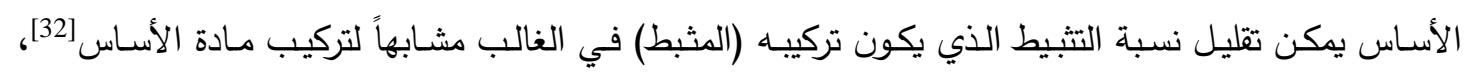

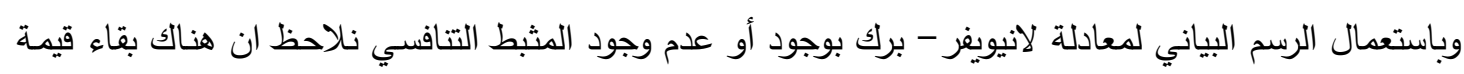

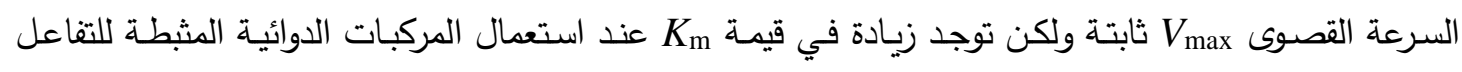
الإنزيمي (أي بمعنى تنخفض ألفة الإنزيم لمـادة الأسـاس)، فقد وجد ان قيمة للمركبات الدوائيسة السيراميد

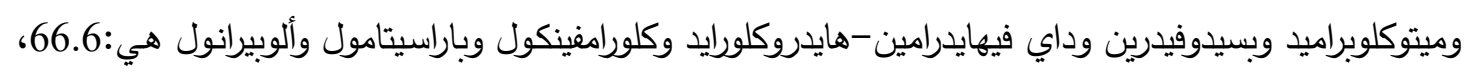

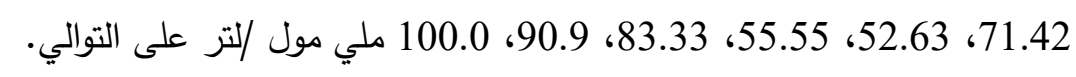

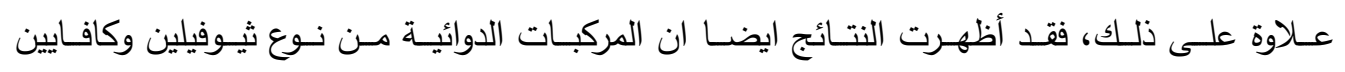

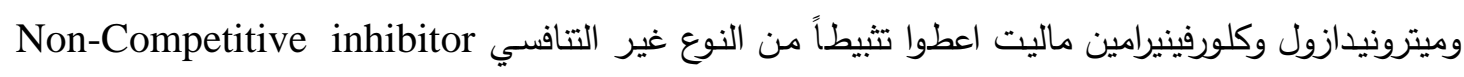

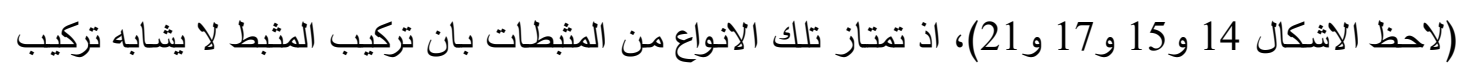

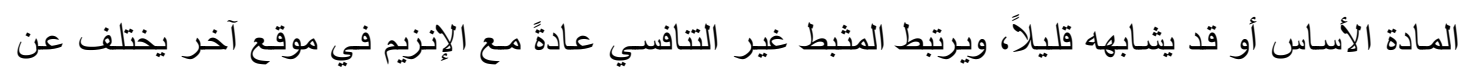

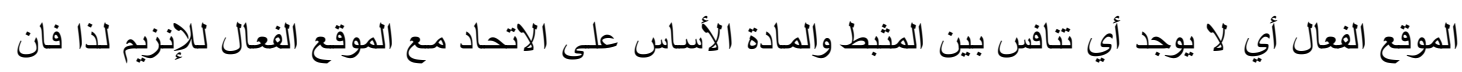

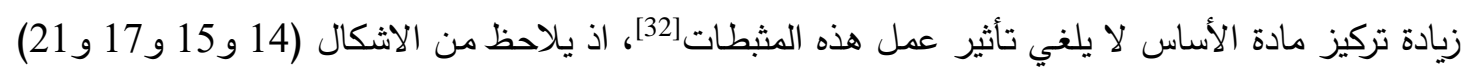

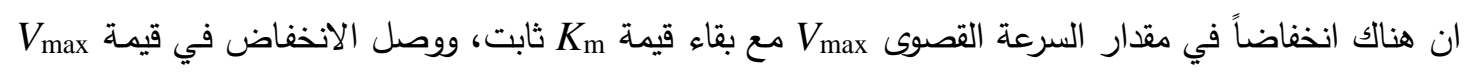

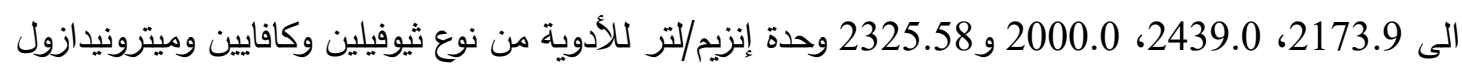
وكلورفينيرامين ماليت على التوالي . إن أي مركب يعمل على تثبيط فعالية إنزيم برولايديز وبنسب مختلفة تعمل على تتبيط عملية بناء الكولاجين وبالتالي تؤثر على وظائف وانسجة الجسم المختلفة، كون إنزيم البرولايديز يدخل بشكل رئيس في بناء

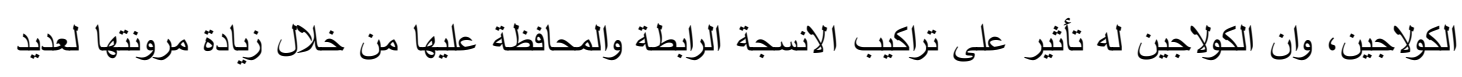

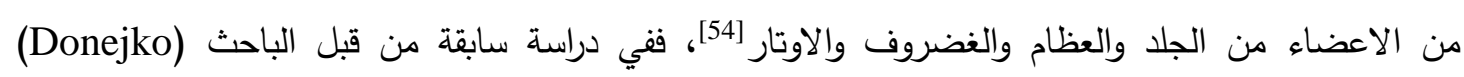

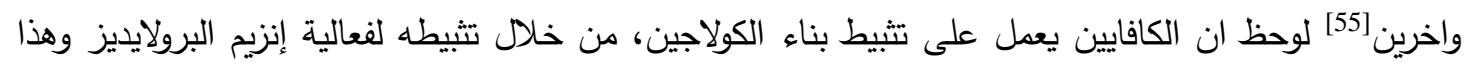

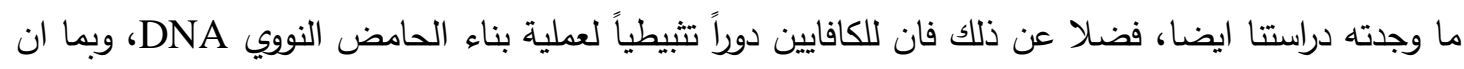

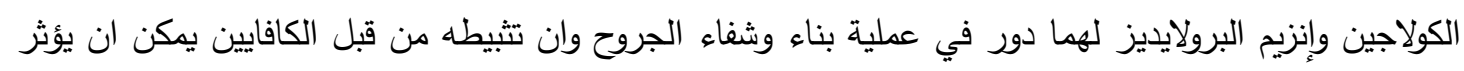


على زيادة سرعة شفاء الجروح [55]. اذ ان الكافايين يعد من المركبات الالكيلويدية (Alkaloids) التي تستعمل مع العديد من الأدوية والذي يكون شائعا ايضا في المشروبات المختلفة وان معدل الاستهلاك اليومي للكافايين

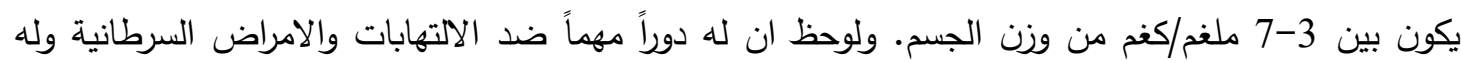
صفات مضادة للأكسدة [56] والذي يشابه في التركيب هو الثيوفيلين الذي اعطى تثبيط ايضا لفعالية الإنزيم وكانت نوعية التثبيط فيه من نوع التثبيط غير التتافسي (لاحظ الثكلين 14 و15). لوحظ في دراسات سابقة ان هناك تأثير تثبيطي للمركب الدوائي كابتوبيرل Captopril على إنزيم البرولايديز المعزول من الكبد والكلية والامعاء الانسان والجرذان (كابتوبيرل دواء يستعمل لمعالجة ارتفاع ضغط الدم)، وله تأثيراً تثبيطياً قليل لإنزيم

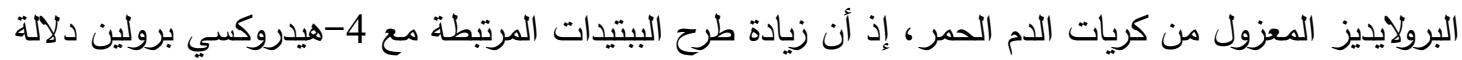

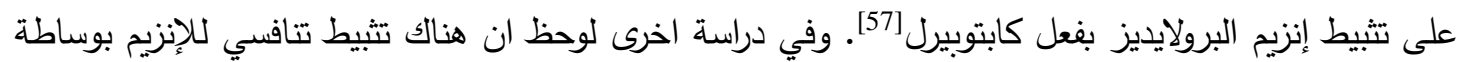

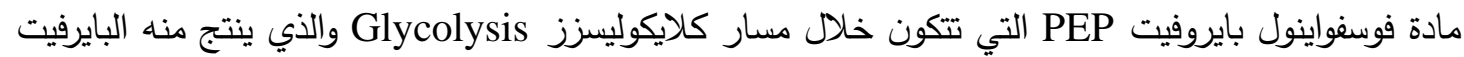
بفعل إنزيم بايروفيت كاينيز [58].
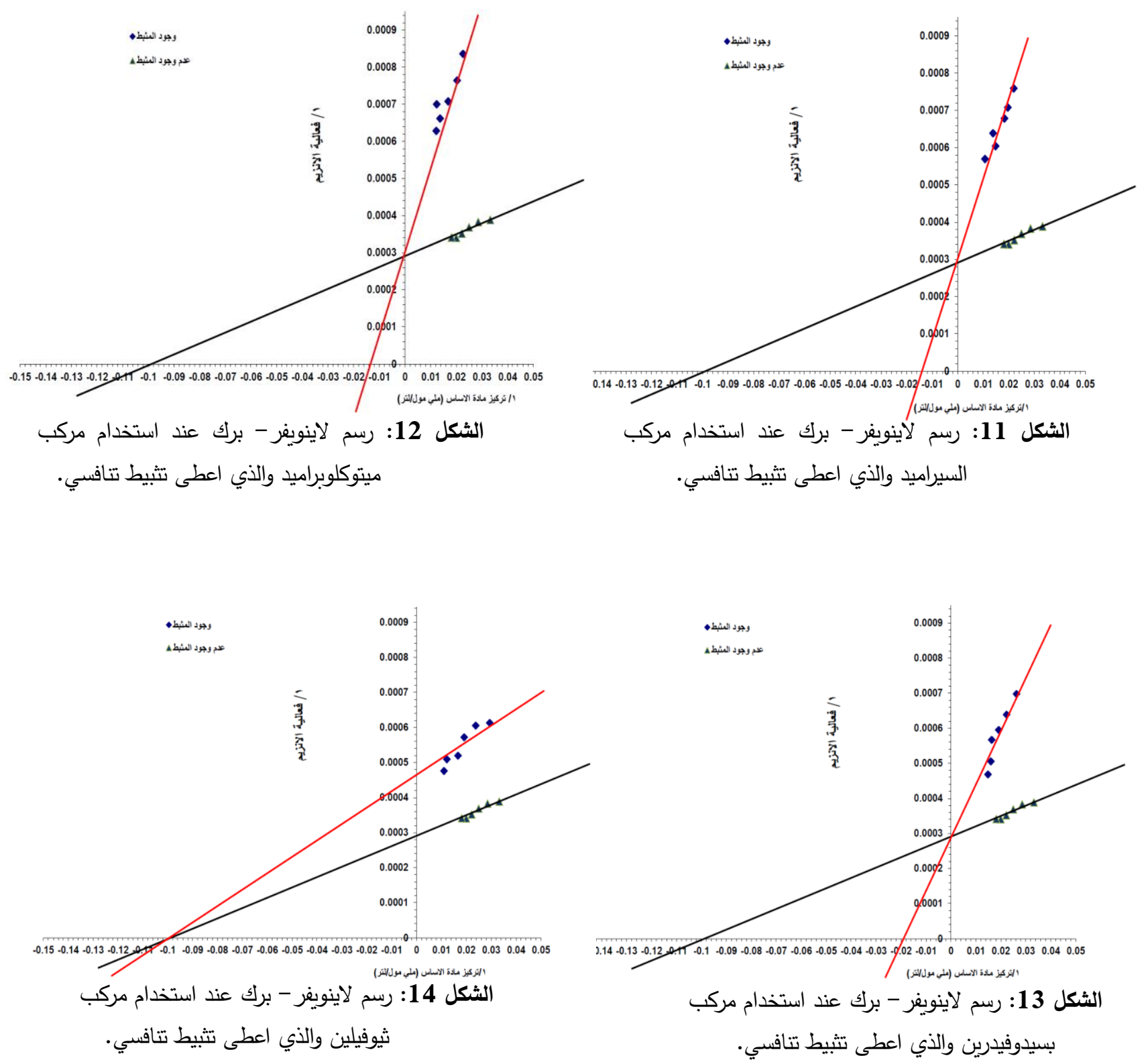

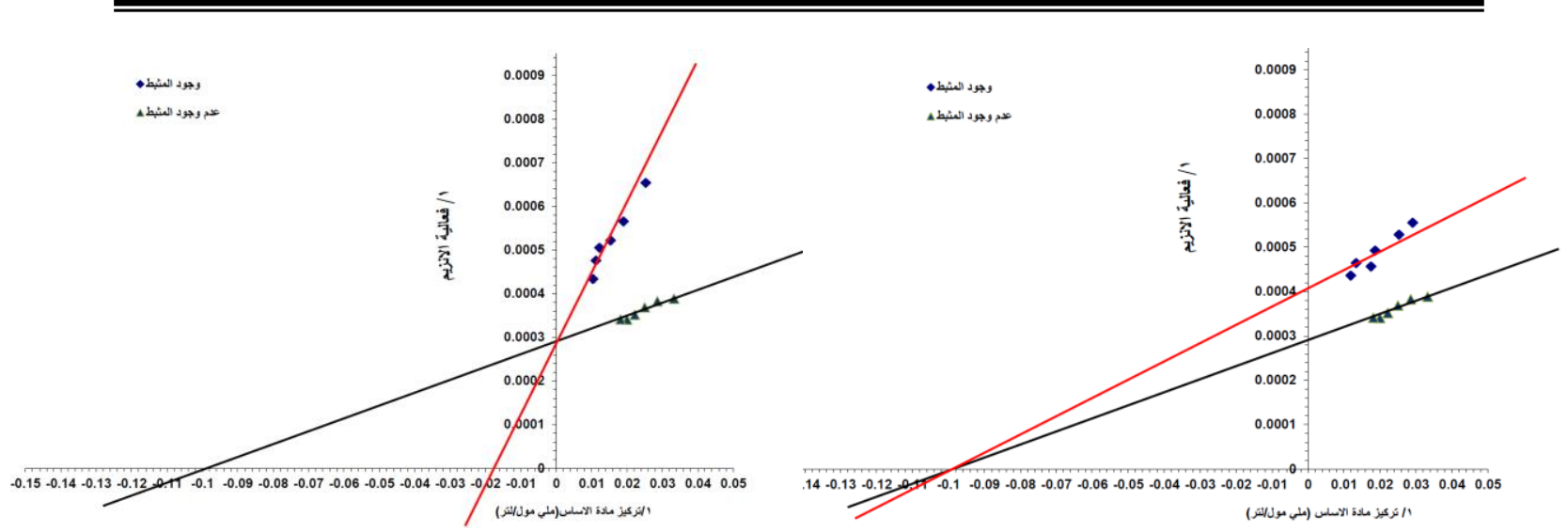

الثكل 16: رسم لاينويغر - برك عند استخدام مركب داي

الثكل 15: رسم لاينويفر - برك عند استخدام مركب

فيهايدرامين-هايدروكلورايد والذي اعطى تثبيط تنافسي.

كافايين والذي اعطى تثبيط غير التتافسي.
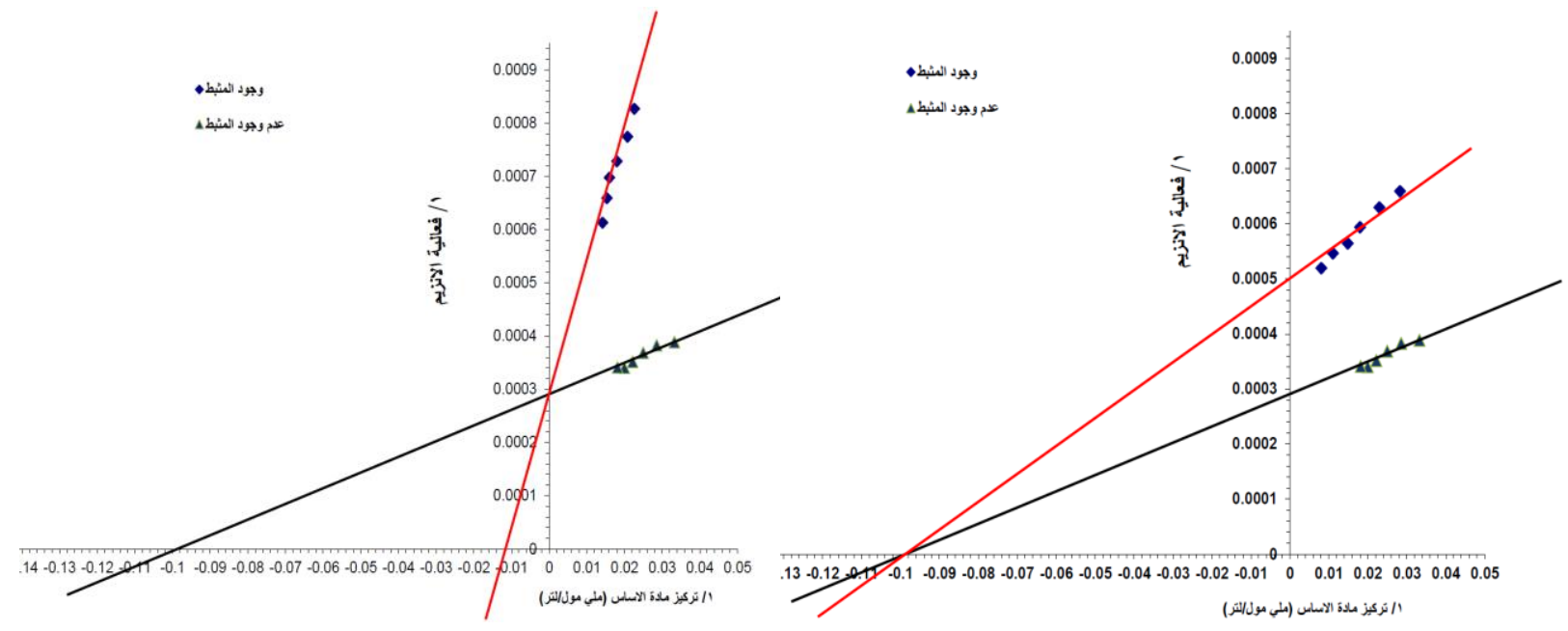

الثكل 18: رسم لاينويغر - برك عند استخدام مركب

كلورامفينكول والذي اعطى تثبيط تتافسي.

الثكل 17: رسم لاينويفر - برك عند استخدام مركب

ميترونيدازول والذي اعطى تثبيط غير التتافسي.

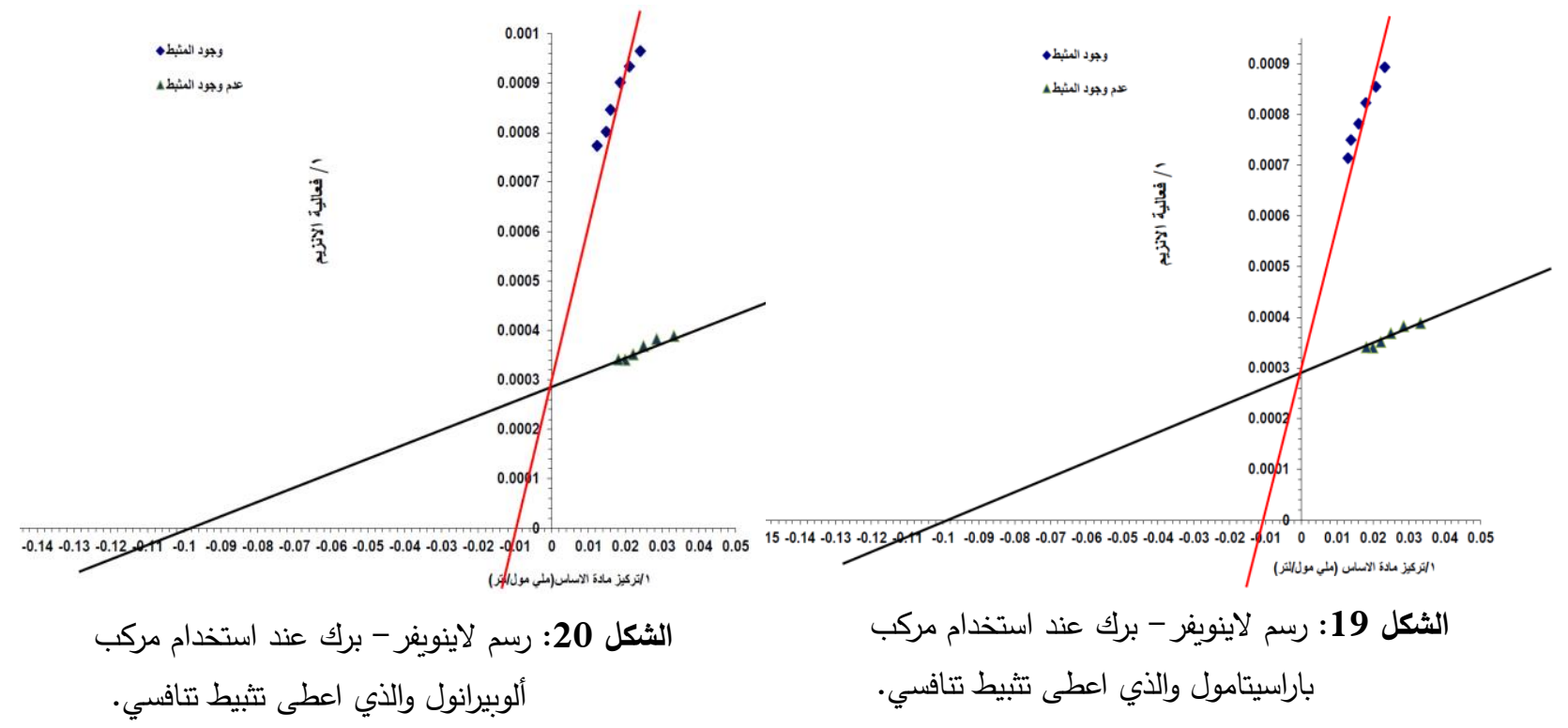




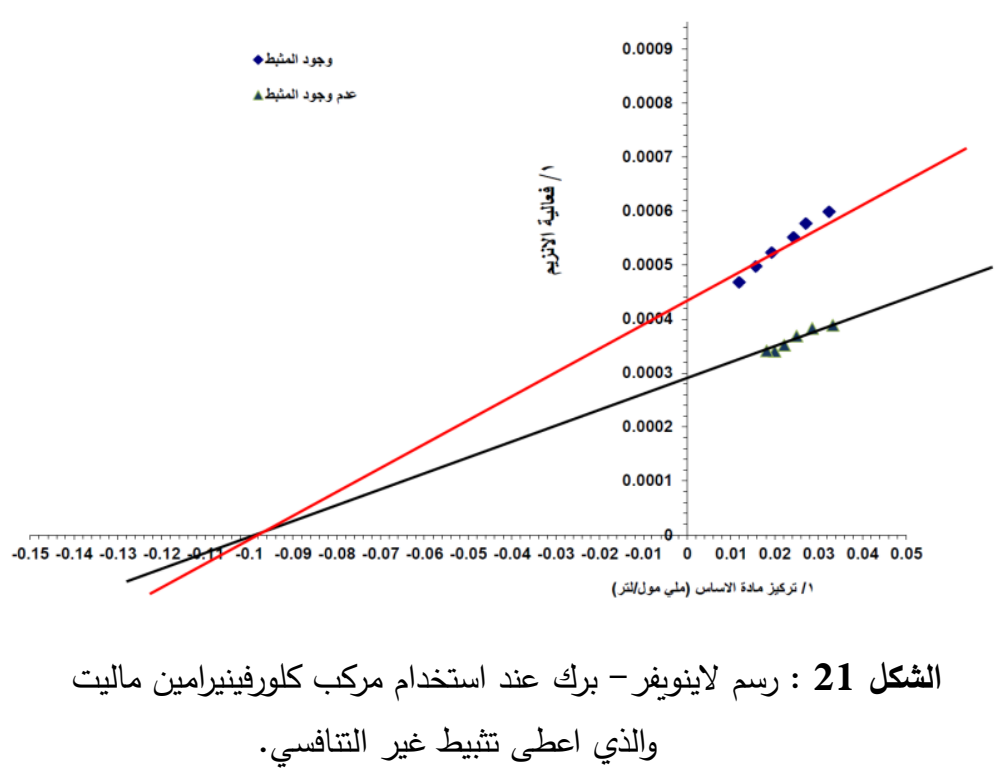

الجهة الممولة للبحث ومكان عمل البحث: قسم الكيمياء/ كلية العلوم/ جامعة الموصل/ الموصل- العراق.

\section{المصادر}

1) Ernst, P., Alim Pharmacol Ther 13,13-18 (1999).

2) Palka, J.A., Phang, J.M, J. Cell Biochem., 67: 166-175(1997).

3) Sell, D.R. and Monnier, V.M., J. Clin. Invest. 85: 380-384(1990).

4) Surazynski, A., Donald, S.P., Cooper, S.K., Whiteside, M.A., Salnikow, K., Liu, Y., Int. J. Cancer. 122(6):1435-40(2008).

5) Hu, C.A., Phang, J.M., Valle, D., Preface. Amino Acids 35:651-652(2008).

6) Osmancik, P., Louckova, A., Kardiol. Pol. 75:295-305(2017).

7) Di Gregoli, K., Johnson, J.L. "Role of Matrix Metalloproteinases in the Development and Progression of Atherosclerosis", Springer. p.425-46(2017).

8) Rabus, M., Demirbag, R., Yildiz, A., Tezcan, O., Yilmaz, R., Ocak, A.R., Arch. Med. Res. 39:519-24(2008).

9) Pirinççi, N., Kaba, M., Geçit, I., Güneş, M., Yüksel, M.B., Tanık, S., Toxicol Ind Health. 32(2):193-9(2016).

10) Gecit, I., Aslan, M., Gunes, M., Pirincci, N., Esen, R., Demir, H., J. Cancer Res. Clin. Oncol. 138(5):739-43(2012).

11) Ercan, A.C., Bahceci, B., Polat, S., Cenker, O.C., Bahceci, I., Koroglu, A., Sahin, K., Hocaoglu, C., Asian J. Psychiatr. 25:118-122(2017).

12) Aslan, M., Duzenli, U., Esen, R., Soyoral, Y.U., Clin Chim Acta. 473:186190(2017).

13) Bhatnager, R., Nanda, S., Dang, A.S., Biomark Med. 12(6):597-606(2018).

14) Lupi A, Tenni R, Rossi A, Cetta G, Forlino A., Amino Acids 35:739-752(2008).

15) Petrikovics, I., Cheng, T.C., Papahadjopoulos, D., Hong, K., Yin, R., DeFrank, J.J., Jaing, J., Song, Z.H. et al., Toxicol. Sci., 57:16-21(2000).

16) Theriot, C.M., Tove, S.R., Grunden, A.M., Adv Appl Microbiol. 68:99132(2009).

17) Simonian, A.L., Grimsley, J.K., Flounders, A.W., Shoeniger, J.S., Cheng, T.-C., DeFrank, J.J. and Wild, J.R.. Anal. Chim. Acta. 442:15-23(2001). 
18) Courtin, P., Nardi, M., Wegmann, U., Joutsjoki, V., Ogier, J.C., Gripon, J.C., Palva, A., Henrich, B. et al., Int. Dairy J. 12:447-454(2002).

19) Perugini, P., Hassan, K., Genta, I., Modena, T., Pavanetto, F., Cetta, G., Zanone, C., Iadarola, P. et al., J. Control Release 102:181-190(2005).

20) Brace,R.A., Cheung, C.Y., Adv. Exp. Med. Biol., 814:49-68(2014).

21) Silberstein, T., Saphier,. M., Mashiach, Y., Paz-Talo, O., Saphier, Q., J. Matern. Fetal. Neonatal Med. 18 (1):88-92(2015).

22) Myara, I., Charpentier, C., Lemonnier, A., Clin. Chim. Acta, 125:193-205(1982).

23) Ozcan, O., Gultepe, M., Ipcioglu, O.M., Bolat, B., Kayadibi, H., Turk. J. Biochem., 32:12-16(2007).

24) Chinard, F.P., J. Biol. Chem., 199:91-95(1952).

25) Suga, K., Kabashima, T., Ito, K., Tsuru, D., Okamura, H., Kataoka, J., Yoshimoto, T., Biosci. Biotechnol. Biochem. 59(11):2087-90(1995).

26) Hui, K.S., Lajtha, A., J. Neurochem. 35(2):489-94(1980).

27) Schacterle, G. R., Pollack, R. L., Anal. Biochem. 51:654-655(1973).

28) Plummer, T.D. "An Introduction to Practical Biochemistry". $2^{\text {nd }}$. Ed., McGrawHill Book Comp., U.K(1978).

29) Robyt, F.J., White, J.B. "Biochemical Techniques, Theory and Practice" books/cole publishing company, Monterey, California(2001).

30) Buritis, C. A., Ashwood, E. R., Bruns, D.E. "Tietz Textbook of Clinical Chemistry and Molecular Diagnostics". By Saunders, an imprint of Elsevier Inc. USA. pp.228, 255(2015).

31) Befani, O., Grippa, E., Saso, L., Turini, P., Mondovi, B., Inflamm. Res., 50:136137(2001).

32) Nelson, D.L., Cox, M.M. "Lehninger, Principles of Biochemistry". 17th ed. W.H.freeman, New York., pp.600,617, 286, 289(2017).

33) Yoshirnoto, T., Matsubara, F., Kawano, E., Tsum, D., J Biochem (Tokyo) 94, 1889(1983).

34) Sjostrom, H., Norén, O., Josefsson, L., Biochim Biophys Acta 327:457(1973).

35) Endo, F., Tanoue, A., Ogata, T., Motohara, K., Matsuda, I., Clin. Chim. Acta. 176(2), 143-9(1988).

36) Fujii, M., Nagaoka, Y., Imamura, S., Shimizu, T., Biosci Biotechnol Biochem. 60 (7):1118-22(1996).

37) Masuda, S., Watanabe, H., Morioka, M., Fujita, Y., Ageta, T., Kodama, H., Acta. Med. Okayama. 48(4):173-9(1994).

38) Pałka, J.A., Rocz. Akad. Med. Bialymst. 41(2):149-60(1996).

39) Vyas, N.K., Nickitenko, A., Rastogi, V.K., Shah, S.S., Quiocho, F.A., Biochemistry 49:547-559(2010).

40) Harbeck, H., Mentlein, R., Eur. J. Biochem. 198:451-458(1991).

41) $\mathrm{Hu}$, M., Cheng, Z., Zheng, L., Pediatr. Res. 53(6):905-14(2003).

42) Mock, W.L., Green, P.C., J Biol Chem. 265(32):19606-10(1990).

43) Sagara, I.M., Ozak, T., Morioka, E., Wada, K., Hondia, K., Hori, A., Matsuya, Y., Br. J. Pharmacol. 165(1):167-182(2012).

44) You, N., Tao, K., Zhao, W., Bao, P., Li, R., You, H., Zhang, M., Methods Find Exp. Clin. Pharmacol. 32(5):3011-8(2010).

45) Aloorkar, N.H., Bhatia, M.S., Ars. Pharm. 52(3):26-34(2011).

46) Lustar, I., Friedland, I. R., Jafri, H.S., Wubbel, L., Ahmad, A., Trujillo, M., McCoig, C.C., and McCraken, G.H., J. Antimicrob. Chemotherapy., 52:651655(2003).

47) Chrzanowski, K., Bielawska, A., Bielawski, K., Pałka, J., Wołczyński, S., Farmaco. 59(9):679-84(2004). 
48) Miltyk, W., Karna, E., Pałka, J., Pol. J. Pharmacol. 48(6):609-13(1996).

49) Konno, K., Tetsuka, T., J. Biochem., 56(6):581-590(1964).

50) Muszyńska, A., Pałka, J. Gorodkiewicz, E.,52( 2):149-155(2000).

51) Surazyński, A., Pałka, J., Wołczyński, S., Mol. Cell Biochem. 220(1-2):95101(2001).

52) Jackson, S.H., Dennis, A.W., Greenberg, M., CMA J. 113, 759-763(1975).

53) Yun, H., Lee, S., Kim, S., Yu, J., Lee, N., Lee, J., Kim, ND., Yu, C., Rho, J., Protein. Pept. Lett. 24(7):617-625(2017).

54) Fratzl, P., "Collagen: Structure and Mechanics" New York, Springer. P.210(2008)

55) Donejko, M., Przylipiak, A., Rysiak, E., Głuszuk, K., Surażyński, A., Development and Therapy. 8:1923-1928(2014).

56) Merighi, S., Benini, A., Mirandola, P, et al., Mol. Pharmacol., 72:395-406(2007).

57) Ganapathy, V., Pashley, S.J., Roesel, R.A., Pashley, D.H., Leibach, F.H., Biochem. Pharmacol. 34(8):1287-91(1985).

58) Karna, E., Pałka, J.A., Mol. Cell. Biochem. 315:61-67(2008). 